\title{
REPORT ON THE ANALYSIS OF THE LARGE PROPAGATION VELOCITIES OBSERVED IN THE FULL-LENGTH SSC DIPOLES*
}

\author{
L. Dresner, J. Winston and M. Lubell \\ Superconducting Super Collider Laboratory ${ }^{\dagger}$ \\ 2550 Beckleymeade Ave. \\ Dallas, TX 75237
}

September 1990

\begin{abstract}
DISCLAIMER
This report was prepared as an account of work sponsored by an agency of the United States Government. Neither the United States Government nor any agency thereof, nor any of their employees, makes any warranty, express or implied, or assumes any legal liability or responsibility for the accuracy, completeness, or usefulness of any information, apparatus, product, or process disclosed, or represents that its use would not infringe privately owned rights. Reference herein to any specific commercial product, process, or service by trade name, trademark, manufacturer, or otherwise does not necessarily constitute or imply its endorsement, recommendation, or favoring by the United States Government or any agency thereof. The views and opinions of authors expressed herein do not necessarily state or reflect those of the United States Government or any agency thereof.
\end{abstract}

${ }^{*}$ Research supported by the Superconducting Supercollider Laboratory under purchase urder SSC- 90 -W01041-MOD-003 with Oak Ridge National Laboratory operated by Martin Marietta Energy Systems, Inc. for the U.S. Department of Energy under contract DE-AC05-840R21400.

†Operated by the Universities Research Association, Inc., for the U.S. Department of Energy under Contract No. DE-AC02-89ER40486. 


\section{CONTENTS}

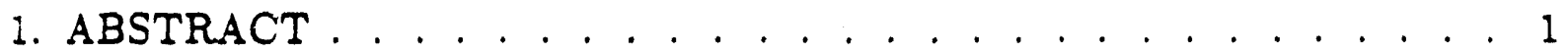

2. INTRODUCTION . . . . . . . . . . . . . . . . . . . . 1

3. PREDICTIONS OF THE CLASSICAL CONDUCTION THEORY . . . . 2

4. SIMILARITY THEORY OF THERMAL HYDRAULIC QUENCHBACK . 5

4.1 BASIC EQUATIONS . . . . . . . . . . . . . . . . . . 7

4.2 FURTHER REDUCTION OF THE EQUATIONS . . . . . . . . . 8

4.3 SIMILARITY SOLUTIONS . . . . . . . . . . . . . . . . . 9

4.4 APPROXIMATE SOLUTION OF EQ. (7) . . . . . . . . . . 10

4.5 PRESSURE AT THE PISTON . . . . . . . . . . . . . . . . 12

4.6 THERMAL HYDRAULIC QUENCHBACK . . . . . . . . . . 12

4.6.1 Time of Onset . . . . . . . . . . . . . . . . . . . . . . 12

4.6.2 Time at Which Entire Conductor Goes Norma' . . . . . . . 14

4.6.3 Thermal Hydraulic Quenchback in the SSC Dipoles . . . . . . . . . . . . . . . . . . 15

5. COMPARISON OF DATA ON SSC DIPOLES WITH THE SIMILARITY THEORY . . . . . . . . . . . . . . . . . . 16

6. DISCUSSION AND RECOMMENDATIONS . . . . . . . . . . . . . 19

REFERENCES . . . . . . . . . . . . . . . . . . . . . . . 25

LIST OF SYMBOLS . . . . . . . . . . . . . . . . . . . . . . . 27

APPENDIX 1: QUENCH PROPAGATION IN A CABLF-IN-CONDUIT FORCE-COOLED SUPERCONDUCTOR-PRELIMINARY RESULTS . . . . . . . . . . . . . . . 29 


\title{
REPORT ON THE ANALYSIS OF THE LARGE PROPAGATION VELOCITIES OBSERVED IN THE FULL-LENGTH SSC TEST DIPOLES
}

\author{
Lawrence Dresner, J. Winston Lue, and M. S. Lubell \\ Oak Ridge National Laboratory, Oak Ridge, Tennessee
}

\section{ABSTRACT}

Very large propagation velocities have been observed in the Superconducting Super Collider (SSC) $17-\mathrm{m}$ dipoles: from $75 \mathrm{~m} / \mathrm{s}$ to $225 \mathrm{~m} / \mathrm{s}$, depending on the current (see Fig. 3 below). These velocities are much larger than those predicted by the classical conduction theory of normal zone propagation. A plausible explanation for such rapid propagation is a hydrodynamic mechanism called thermal hydraulic quenchback (THQ) that has been proposed by Luongo et al. ${ }^{1}$ This report supplies an approximate analytic theory of THQ, which is used to analyze the data taisen on the SSC $17-\mathrm{m}$ dipoles. It is concluded that THQ in the helium in the interstices of the cable can explain the large propagation velocities observed. Additional experiments are proposed to test the hydrodyaamic explanation.

\section{INTRODUCTION}

In the paper "Development of Spontaneous Quenches in Full-Length SSC R\&D Dipoles" by A. Devred et al., ${ }^{2}$ the following statement appears: "The major surprise of magnet $\mathrm{DD} 0010$ was the high propagation velocities: $100 \mathrm{~m} \cdot \mathrm{s}^{-1}$ on the turn where the quench originated. They appear to be even faster on magnet DD0012: $150 \mathrm{~m} \cdot \mathrm{s}^{-1}$ on the turn where the quench originated ... how can the absolute values of these velocities be explained?" After posing this question, Devred et al. go on to say, "Because the classical description of the longiludinal propagation based on the Fourier conduction along the conduntor copper could not predict such values, we must therefore find another mechanism that speeds up the propagation. One possibility is the effect of a [thermal] hydraulic quenchback, as described [by Luongo, Loyd, Chen, and Peck] in ref. 1, the phenomenon taking place in the helium channel between the bore tube and the coil. More calculations are needed to validate the application of this model to our configuration." [Emphasis added.] 
Part of this report supplies these calculations in the form of an analytic study of THQ carried out using a method of treating compressible flow in long tubes that wa pioneered at Oak Ridge National Laboratory ${ }^{3-5}$ and is based on similarity solutions. ${ }^{3}$ Although the details of this study are complex, the results are simple formulas.

Luongo et al. ${ }^{1}$ discovered THQ in the course of a numerical simulation of helium expulsion from a cable-in-conduit conductor, and the phenomenon has not yet been observed in the laboratory. Therefore, the predictions of the theory remain unverified by experiment. In this report they are compared with the available data on the SSC magnets to see how certain it is that THQ is responsible for the large propagation velocities measured in the 17-m test dipoles. In addition, several new experiments that may further clarify this issue are proposed.

Finally, because there has been some confusion as to what the predictions of the classical conduction theory actually are, an introductory section describing the application of that theory to the SSC dipoles has been included in this report.

Symbols are defined in a table at the end of the report. Within each section, equations are numbered consecutively. Cross-references to equations are numbered thus: Eq. (4.2) means Eq. (2) of Sect. 4.

\section{PREDICTIONS OF THE CLASSICAL CONDUCTION THEORY}

In the classical conduction theory of normal zone propagation, the expansion of the normal zone is caused by heat conduction through the copper matrix from the hot normal zone to the adjacent cold superconductor. Figure 1 shows the dimensionless propagation velocity $v / v$. plotted against the dimensionlesi current $i=I / I_{c}$. Here the fiducial velocity $v_{*}$ is given by

$$
v_{*}=2 \frac{J_{c}}{S}\left(\frac{\rho_{c} k}{T_{c}-T_{b}}\right)^{1 / 2} .
$$

The curves in Fig. 1 were calculated using the formulas from refs. 7 and 8 . The curves are labeled from right io left with values of the Stekly parameter $\alpha=1.5$, $2,3,5,10,20,30,50,100,200,300,500,1000$, and $\infty$. The Stekly parameter is defined by

$$
\alpha=\frac{\rho_{e} I_{c}^{2}}{f A P h\left(T_{c}-T_{b}\right)}
$$




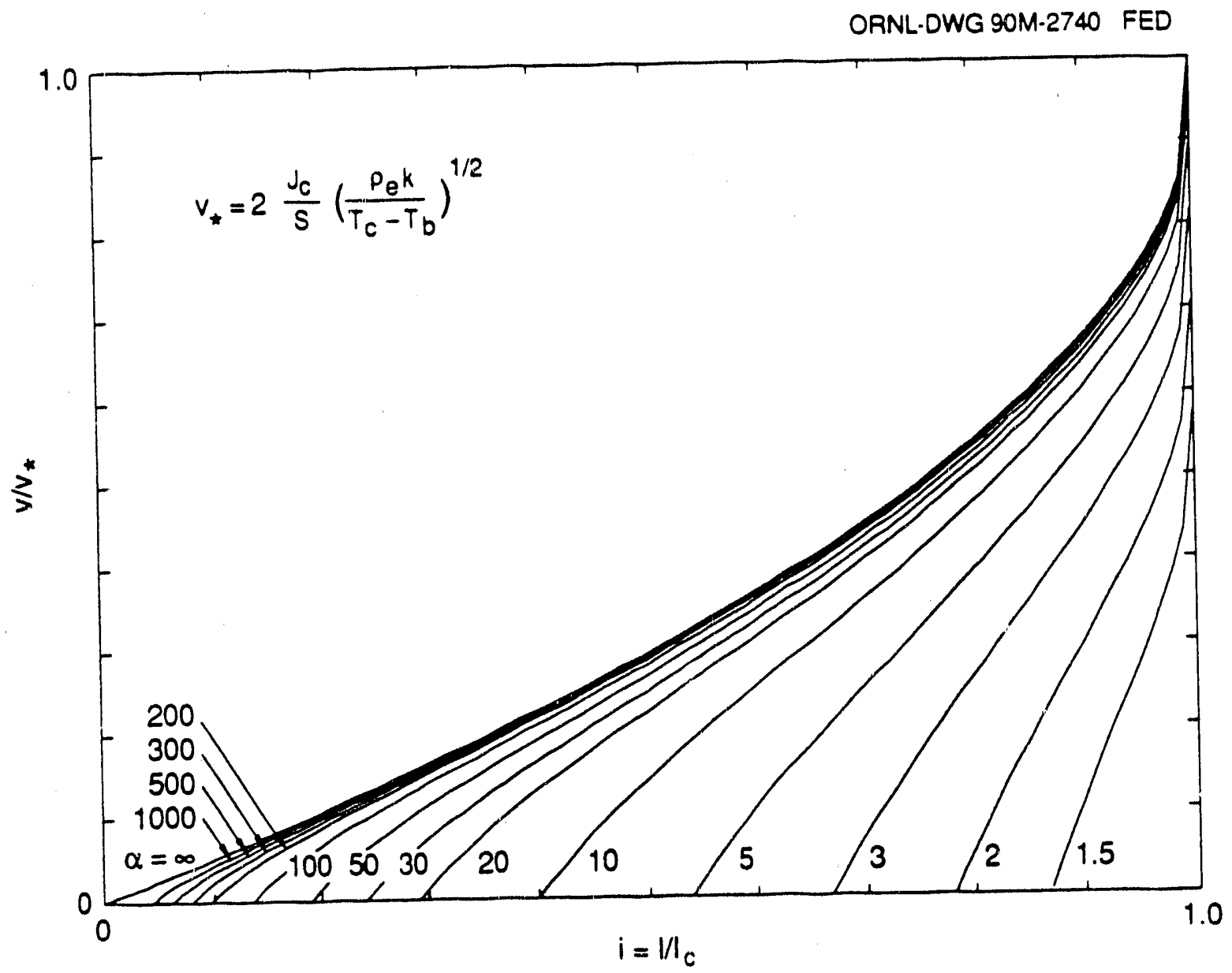

Fig. 1. The dimensionless propagation velocity $v / v$ * plotted against the dimensionless current $i=I / I_{c}$ according to the classical conduction theory. The parameter $\alpha$ labeling the curves is the Stekly number [see Eq. (3.2)]. 
The curves in Fig. 1 include the effect of current sharing but are based on the assumption that the thermal conductivity $k$ and the volumetric beat capacity $S=$ $\rho C_{p}$ are independent of temperature. When $i=1, v / v_{*}=\sqrt{(\alpha-1) / \alpha}$.

In ref. 2 , the following conductor characteristics are noted:

$\begin{array}{ll}\text { Number of strands } & =2.3 \\ \text { Strand diameter } & =0.808 \mathrm{~mm} \\ \mathrm{Cu} / \mathrm{SC} \text { ratio } & =1.6(f=0.6154) \\ \text { Residual resistance ratio }(\mathrm{RRR}) & =79 \\ I_{c}(\text { at } 5 \mathrm{~T}, 4.22 \mathrm{~K}) & =10,790 \mathrm{~A}\end{array}$

Quench 10, which we analyze in detail by way of example, occurred at $6544 \mathrm{~A}$ (1.018 of short sample), $4.28 \mathrm{~K}$, and $0.34 \mathrm{MPa}$. So for this quench, $i=1$ and $v_{\text {. }}=\sqrt{(\alpha-1) / \alpha}$

According to Peoples, ${ }^{9}$ the peak field at the conductor is $7 \mathrm{~T}$. Thus, $T_{c}=6.0 \mathrm{~K}$. Since $I / I_{c}=1.018, I_{c}=6428 \mathrm{~A}$. Since the total conductor area is $11.79 \mathrm{~mm}^{2}$, $J_{c}=5.452 \times 10^{8} \mathrm{~A} / \mathrm{m}^{2}$.

Next, we need to find the volumetric heat capacity $S$ of the conductor. We use the following data for $\mathrm{NbTi}$ :

$$
\begin{aligned}
& C_{p}=\gamma T+\beta T^{3} \quad \text { (normal), } \\
& C_{p}=\left[\beta+3 \gamma / T_{c 0}^{2}\right] T^{3}+\gamma H T / B_{\mathrm{c} 2} \quad \text { (superconducting), }
\end{aligned}
$$

where

$$
\begin{aligned}
\gamma & =0.145 \mathrm{~mJ} \cdot \mathrm{g}^{-1} \cdot \mathrm{K}^{-2}, \\
\beta & =2.3 \times 10^{-3} \mathrm{~mJ} \cdot \mathrm{g}^{-1} \cdot \mathrm{K}^{-4}, \\
T_{c 0} & =9.09 \mathrm{~K}, \\
H_{c 2} & =9.67 \mathrm{~T} .
\end{aligned}
$$

These data are from ref. 10: the value of $H_{c 2}$ has been obtained from a best fit to specific heat measurements at $7 \mathrm{~T}$. The density of $\mathrm{NbTi}$ is $6 \mathrm{~g} \cdot \mathrm{cm}^{-3}$. The corresponding data for copper are:

$$
\begin{aligned}
C_{p} & =\gamma T+\beta T^{3}, \\
\gamma & =1.1 \times 10^{-5} \mathrm{~J} \cdot \mathrm{g}^{-1} \cdot \mathrm{K}^{-2}, \\
\beta & =7.44 \times 10^{-7} \mathrm{~J} \cdot \mathrm{g}^{-1} \cdot \mathrm{K}^{-4}
\end{aligned}
$$


These data are from ref. 11. The density of copper is $8.96 \mathrm{~g} \cdot \mathrm{cm}^{-3}$. With these data we find

$$
\begin{aligned}
& S=A T+B T^{3}, \\
& A=0.3030 \mathrm{~mJ} \cdot \mathrm{cm}^{-3} \cdot \mathrm{K}^{-3}, \\
& B=0.02156 \mathrm{~mJ} \cdot \mathrm{cm}^{-3} \cdot \mathrm{K}^{-4}
\end{aligned}
$$

In Eq. (1) we use for $S$ an average value equal to the enthaipy difference $H_{c}-H_{b}$ calculated by integrating Eq. (5) divided by the temperature difference $T_{c}-T_{b}$. Then we find $S=4567 \mathrm{~J} \cdot \mathrm{m}^{-3} \cdot \mathrm{K}^{-1}$.

We use the Wiedemann-Franz law to find the product $k \rho_{e}$ at the average temperature $\left(T_{c}+T_{b}\right) / 2=5.140 \mathrm{~K}$. Then finally, $v_{\star}=64.60 \mathrm{~m} / \mathrm{s}$.

We need to estimate $\alpha$. The resistivity of the copper including magnetoresistance at $7 \mathrm{~T}$ is

$$
\rho_{e}=1.6 \mu \Omega \cdot \mathrm{cm} / 79+4.8 \times 10^{-9} B \Omega \cdot \mathrm{cm}=5.385 \times 10^{-8} \Omega \cdot \mathrm{cm} .
$$

The maximum wetted perimeter $P=58.38 \mathrm{~mm}$, the perimeter of the strands, and $A=11.79 \mathrm{~mm}^{2}$. This gives $\alpha=30.54$ when $h=0.1 \mathrm{~W} \cdot \mathrm{cm}^{-2} \cdot \mathrm{K}^{-1}$, a typical value. Since $i=1, v=0.9835$ and $v_{\bullet}=63.53 \mathrm{~m} / \mathrm{s}$. The experimental value of $142 \mathrm{~m} / \mathrm{s}$ for the propagation velocity in turn 16 is more than twice this value.

It is not our intention here to repeat the analysis reported by the authors of ref. 1 . This section has been included here to dispel any remaining doubts as to what the predictions of the classical conduction theory actually are. It seems clear that this theory cannot account for the high velocities observed. But it is equally clear from the large value of $v_{*}$ in this example that conduction may play a subordinate role in the propagation process even if the main role is played by thermal hydraulic quenchback.

\section{SIMILARITY THEORY OF THERMAL HYDRAULIC QUENCHBACK}

With the increasing popularity of cable-in-conduit superconductors has come increasing attention to the problems of their quench protection-problems such as the rise in internal pressure, the expulsion of helium from the ends of a hydraulic path, and the growth of normal zones. Recently, while studying these problems by means of numerical simulation, Luongo et al. ${ }^{1}$ discovered a new phenomenon that 
they called THQ. They saw fluid elements far from a normal zone being driven through the interstices of the cable by the expansion of the heated helium in the normal zone. Because of the compression of these fluid elements and their friction with the strands of the cable, their temperatures rose. When their temperatures reached the current-sharing threshold, the strands wetted by them became resistive. Then, quite suddenly, very long segments of conductor became normal, causing the propagation velocity of the normal front to jump to very large values.

While the numerical study has pointed out the existence of THQ, it has not made clear the interplay of the many parameters that control the phenomenon. Over the past decade, Dresner has developed an analytic method of dealing with such problems based on similarity solutions. ${ }^{3-5}$ While less comprehensive than the numerical calculations, this method has the virtue of representing the quantities of interest by means of simple formulas that show at a glance their dependence on the various parameters of the problem. It is applied here to the problem of THQ.

When a nonrecovering normal zone appears in a cable-in-conduit superconductor, the pressure in the conductor rises, helium is expelled from its ends, and the normal zone grows in size. A variety of coupled physic : processes, each simple in itself, underlies these three manifestations of ihe nonrecovering normal zone. Thus, beating of the belium by the normal conductor causes its pressure to rise, but the rise in pressure is limited by the expansion of the belium. The expansion of the belium is restrained by inertia and by turbulent friction with the walls and the wires of the conductor. This partially restrained expansion determines the rates of pressure rise and thermal expulsion. These rates are also determined by the power input to the helium, which in turn depends on the size of the normal zone. The normal zone grows with time, spreading because of hent transfer from the normal part of the conductor to the part that is still superconducting. Such heat transfer takes place by conduction through the copper matrix and by the action of the expanding warm belium.

The problem we face is further complicated by the fact that the helium and the rnetal are not in thermal equilibrium, so that the interfacial heat transfer between these two phases nay need to be taken into account. Furthermore, the helium, being in a state close to its critical state, may exhibit rapid densily changes. Finally, the specific heat, thermal conductivity, and normal-state resistivity of the metal are strong functions of the temperature.

This brief summary shows the reader that a complete calculation of quench pressure, thermal expulsion rate, and propagation velocity can only be carried out 
on a large computer, and even then it is a rather daunting task. A useful preliminary, having considerable valuc in its own right, would be the discovery of simple, easily solved problems that describe roughly but reliably what happens. One such problem, on which this report is based, is to calculate the pressure rise and the motion of the cold helium in a long, slender pipe induced by a piston moving down the pipe. The motion of the piston is imagined to be externally imposed and such that the displacement of the piston varies as a power of the elapsed time.

\subsection{BASIC EQUATIONS}

The key to making the calculations is the very large length-to-diameter $(L / D)$ ratio of the helium volume inside the conductor. Uuring a quench, the Joule heating raises the pressure of the helium. The helium tries to relieve this pressure by expanding, but its expansion is opposed by friction with the wires and the walls and by the inertia of the fluid. Because of the very large $L / D$ ratio, the pressure gradient in the helium is almost entirely expended in overcoming friction, and accordingly we neglect the inertia of the fluid. This simplification enables us to obtain formulas that show explicitly the dependence of the fluid velocity on the various parameters of the conductor.

The llow equations (continuity, momentum, energy) for a heated pipe are

$$
\begin{gathered}
\frac{d \rho}{d t}+\rho \frac{\partial v}{\partial z}=0 \\
\rho \frac{d v}{d t}=-\frac{\partial p}{\partial z}-\rho F, \\
\rho \frac{d}{d t}\left(e+\frac{v^{2}}{2}\right)=-\frac{\partial}{\partial z}(p v)+Q,
\end{gathered}
$$

where $F$, the frictional force per unit mass, is given by $F=2 f v^{2} / D$. The frictional force appears in the momentum equation (1b) just as any external force would, but not in the energy equation (1c) because the work done by the flis against the frictional force is not removed from the fluid (as it would be if the work were against an external force) but is returned to it as heat.

If we multiply Eq. (1b) by $v$ and subtract it from Eq. (1c), we find, after using Eq. (1a) and the second law of thermodynamics, $T d s=d e+p d \tau$, that

$$
T \frac{d s}{d t}=\frac{Q}{\rho}+F v .
$$


The term $F v$ on the right-hand side of Eq. (2) represents entropy production due to irreversible conversion by friction of kinetic energy to internal energy. Had the term $-\rho F v$ been present on the right-hand side of Eq. (1c), as it would have been if $F$ were an external force, then the term $F v$ would not appear in Eq. (2).

The basic assumption of this method is that the frictional forces greatly dominate inertial forces in a long, narrow tube. This means that the left-hand side of Eq. (1b) is very much less than either term on the right. In other words, the pressure gradient expends itself in overcoming friction, not in accelerating the fluid. Hence, we set $d v / d t=0$ in Eq. (1b). We can eliminate the derivative of $\rho$ from Eq. (1a) using the thermodynamic identity $d \rho=d p / c^{2}-\left(B \rho / C_{p}\right) T d s$ so that

$$
\frac{1}{\rho} \frac{d \rho}{d t}=\frac{1}{\rho c^{2}} \frac{d p}{d t}-\frac{B}{C_{p}}\left(\frac{Q}{\rho}+F v\right) .
$$

Using Eqs. (1a), (1b), and (3), we find

$$
\frac{\partial v}{\partial z}+\frac{1}{\rho c^{2}} \frac{\partial p}{\partial t}=\frac{B}{C_{p}}\left[\frac{Q}{\rho}+F v\left(1+\frac{C_{p}}{B c^{2}}\right)\right] .
$$

Finally, consulting NBS-631, we find that $B c^{2} / C_{p}$ is always close to 1 .

\subsection{FURTHER REDUCTION OF THE EQUATIONS}

We use Eq. (1b), with its left-hand side set equal to zero, and Eq. (4) to calculate the pressure rise and motion induced in the belium in a long, slender pipe caused by a thermal perturbation near its center. We simulate the effect of the thermal perturbation and the subsequent growth of a nonrecovering normal zone with a piston whose displacement $Z$ is proportional to a power $n$ of the time: $Z=X t^{n}$. Beyond the piston, the Joule power density $Q$ is zero.

Early, when not much helium bas been expelled from the pipe, the helium remains on the high-density side of the pseudo-critical curve and behaves like a liquid. We therefore take the physical properties $\rho$ and $c$ to be constants. From now on, we interpret $p$ as the pressure rise above ambient pressure. Finally, to simplify the appearance of the equations, we work in this section and in Sects. 4.34.5 in a special system of units in which $\rho=c=D / 4 f=1$. If we now eliminate $p$ between Eqs. (1b) and (4), we obtain (in special units!)

$$
\frac{\partial^{2} v}{\partial z^{2}}=v \frac{\partial v}{\partial t}+3 m v^{2} \frac{\partial v}{\partial z},
$$

where 


$$
m=\frac{1}{2}\left(1+\frac{B c^{2}}{C_{p}}\right) \text {. }
$$

The boundary and initial conditions under which Eq. (5a) must be solved are

$$
v(z, 0)=0, v(\infty, t)=0, v(Z, t)=\dot{Z} .
$$

Strictly speaking, the second boundary condition refers to a semi-infinite pipe, which is what we shall consider for the time being. Later, we shall deal with the problem of applying the solutions for the semi-infinite pipe to pipes of finite length.

It will prove convenient in what follows to use a system of coordinates that move with the piston. Accordingly, we introduce the new space variable $\zeta=z-Z(t)$ in place of $z$. Then Eq. (5) and (6) become

$$
\frac{\partial^{2} v}{\partial \zeta^{2}}=v \frac{\partial v}{\partial t}+\left(3 m v^{2}-\dot{Z} v\right) \frac{\partial v}{\partial \zeta}
$$

and

$$
v(\zeta, 0)=0, v(\infty, t)=0, v(0, t)=\dot{Z}=n X t^{n-1}
$$

\subsection{SIMILARITY SOLUTIONS*}

If the last term on the right-hand side of Eq. (7) is small compared with the other two terms, then Eq. (7) takes the form

$$
\frac{\partial^{2} v}{\partial \zeta^{2}}=v \frac{\partial v}{\partial t}
$$

Equation (9) is invarias t $t 5$ the one-parameter family of one-parameter groups of stretching transformations

$$
\begin{aligned}
v^{\prime} & =\lambda^{\alpha} v, \\
t^{\prime} & =\lambda^{\beta} t, \quad 0<\lambda<\infty, \\
\zeta^{\prime} & =\lambda \zeta,
\end{aligned}
$$

where $\alpha$ and $\beta$ are constrained by the linear relation

$$
\alpha-\beta=-2 \text {. }
$$

\footnotetext{
*A good general reference to the material in this and the next section can be found in ref. 6 .
} 
The parameter $\lambda$ labels the transformations of individual groups; the parameter $\alpha$ labels the groups of the family. Solutions invariant to one group of the family (similarity solutions) have the form

$$
v=t^{\alpha / \beta} y\left(\zeta / t^{1 / \beta}\right)
$$

where $y$ is an as yet undetermined function of the single variable $x=\zeta / t^{1 / \beta}$. If we substitute Eq. (12) into Eq. (9), we obtain the ordinary differential equation

$$
\beta \ddot{y}+x y \dot{y}-\alpha y^{2}=0
$$

for $y(x)$.

If we compare Eq. (12) with the last boundary condition in Eq. (8), we see that $n-1=\alpha / \beta$. Thus $\beta=2 /(2-n)$ and $\alpha=2(n-1) /(2-n)$. The parameter $\beta$ must be positive so that the similarity solution (12) represents a velocity distribution that spreads out as time progresses. Thus $n$ must be $<2$. Furthermore, $n$ must be $>0$ if $Z=X t^{n}$ is to describe a motion of the piston in the direction of increasing $z$. The similarity solutions we shall be studying therefore only apply to exponents in the range $0<n<2$. The boundary corditions (8) now become

$$
y(\infty)=0, \quad y(0)=n X .
$$

\subsection{APPROXIMATE SOLLTION OF EQ. (7)}

If we imagine that the solution (12) to Eq. (9) is known, we can use it as a jumping-off point for the approximate solution of Eq. (7) by taking

$$
v(\zeta, t)=t^{\alpha / \beta} y[\zeta / k(t)],
$$

where $y(x)$ is the solution of Eqs. (13) and (14) and $k(t)$ is a function yet to be determined. Since Eq. (15) is not the exact solution of Eq. (7), we cannot find $k(t)$ by substituting Eq. (15) into Eq. (7). Instead, we reduce the information content of Eq. (7) by integrating it over $\zeta$ from 0 to $\infty$ and then substitute Eq. (15) for $v$. We find

$$
\left(\frac{1}{2} \int_{0}^{\infty} y^{2} d x\right) \frac{d}{d t}\left(t^{2 \alpha / \beta} k\right)=\frac{t^{\alpha / \beta}[-\dot{y}(0)]}{k}+\left(m-\frac{1}{2}\right) \dot{z}^{3}
$$


If we integrate Eq. (13) over $x$ from 0 to $\infty$ and integrate once by parts, we find that

$$
-\beta \dot{y}(0)=(2 \alpha+1) \cdot \frac{1}{2} \int_{0}^{\infty} y^{2} d x
$$

Because Eq. (13) is invariant to the associated group ${ }^{6}$

$$
\begin{aligned}
& y^{\prime}=\mu^{-2} y, \\
& x^{\prime}=\mu x,
\end{aligned}
$$

it can easily be shown that

$$
\frac{1}{2} \int_{0}^{\infty} y^{2} d x /[y(0)]^{3 / 2}=\left(\frac{\beta}{\alpha+\beta}\right)^{3 / 2} A(\alpha) ;
$$

that is, that the ratio on the left is independent of $y(0)$ and depends only on $\alpha$. (The factor $[\beta /(\alpha+\beta)]^{3 / 2}$ has been inserted on the right for convenience.) Inserting Eqs. (14), (17), and (19) into Eq. (16), we find that the latter becomes

$$
\frac{d}{d t}\left(t^{2 \alpha / \beta} k\right)=\frac{2 \alpha+1}{\beta} \cdot \frac{t^{\alpha / \beta}}{k}+\left(m-\frac{1}{2}\right) t^{3 \alpha / \beta} n^{3} X^{3 / 2} A^{-1}
$$

Equation (20) can be solved by choosing $k t^{2 \alpha / \beta}$ as the new dependent variable and separating variables. After a tedious computation we find

$$
\xi \eta-\ln (1+\xi \eta)=\xi^{2} / 2
$$

where

$$
\xi=\frac{[m-(1 / 2)] n^{3} \beta}{A(2 \alpha+1)} X^{3 / 2} t^{3 n / 2-1}
$$

and

$$
\eta=k / t^{1 / \beta}
$$

Some values of $\xi$ and $\eta$ are shown in Table 1 .

The function $\eta$ can be used to judge the validity of the solution we have obtained, for only if $\eta$ is not too large compared with 1 will the solution (15) be dependable. This sets a limit on the size of $\xi$, which in turn sets a limit on the elapsed time $t$.

Finally, $\xi$ will be small when $t$ is small only if $n>\frac{2}{3}$, so the solution we have found is only valid in the range $\frac{2}{3}<n<2\left(\frac{3}{2}<\beta<\infty,-\frac{1}{2}<\alpha<\infty\right)$. 
Table 1. Some values of $\xi$ and $\eta$

\begin{tabular}{cc}
\hline$\xi$ & $\eta$ \\
\hline 0.010 & 1.003 \\
0.030 & 1.010 \\
0.097 & 1.033 \\
0.274 & 1.093 \\
0.783 & 1.276 \\
1.343 & 1.490 \\
2.533 & 1.974 \\
2.598 & 2.001 \\
\hline
\end{tabular}

\subsection{PRESSURE AT THE PISTON}

According to Eq. (1b) without the inertial term,

$$
\begin{aligned}
p(0, t) & =\frac{1}{2} \int_{0}^{\infty} v^{2} d \zeta \\
& =\eta A X^{3 / 2} t^{\frac{3}{3} n-1}=\eta A Z^{3 / 2} t^{-1}
\end{aligned}
$$

when we use Eqs. (12), (14), and (19). In ordinary units this becomes

$$
p(0, t)=\eta A \cdot \rho c^{2}\left(\frac{4 f Z}{D}\right)^{3 / 2}\left(\frac{D}{4 f c t}\right),
$$

where the dependence on $n$ is now only through the constants $\eta$ and $A$.

As it happens, Eq. (13) can be solved analytically when $n=\frac{2}{3}$ and when $n=2$, and in these cases, $A=\pi / 6$ and $2 / \sqrt{3}$, respectively. Numerical calculations, which will not be described here, show that $A$ varies almost perfectly linearly between these extremes, and so $A$ will be given by the interpolation formula

$$
A=\left(\frac{\sqrt{3}}{2}-\frac{\pi}{8}\right) n+\left(\frac{\pi}{4}-\frac{\sqrt{3}}{3}\right), \frac{2}{3}<n<2 .
$$

\subsection{THERMAL HYDRAULIC QUENCHBACK}

\subsubsection{Time of Onset,}

The first fluid element to reach $T_{c}$, will be the one adjacent to the piston because it has the largest velocity and the highest pressure of all. The infinitesimal increment 
of work done in a time $d t$ on this fluid element of length $d z$ in overcoming its friction with the surfaces internal to the jacket is

$$
\frac{f}{2} \rho \dot{Z}^{2} \cdot P d z \cdot \dot{Z} d t
$$

Here the first factor is the wall shear stress, the second factor is the wetted perimeter, and the third factor is the displacement of the piston. If we divide this quantity by $\rho A_{\text {He }} d z$, the mass of the fluid element, and integrate over time from 0 to $t$, we get the specific frictional work $W$ :

$$
W=\frac{2 f}{D} \int_{0}^{t} \dot{z}^{3} d t
$$

The temperature rise due to this work is $W / C_{p}$. If we assume that this temperature rise and that caused by compression are additive, we can write for the overall temperature rise at the piston

$$
\Delta T=\frac{2 f}{D C_{p}} \int_{0}^{t} \dot{Z}^{3} d t+\eta A \rho c^{2}\left(\frac{4 f Z}{D}\right)^{3 / 2}\left(\frac{D}{4 f c t}\right)\left(\frac{\partial T}{\partial p}\right)_{V} .
$$

The time at which $\Delta T$ equals $T_{c a}-T_{b}$ marks the onset of thermal hydraulic quenchback. Equation (27) can be written in the convenient form

$$
\frac{C_{p} \Delta T}{c^{2}}=\frac{2 f}{D c^{2}} \int_{0}^{t} \dot{Z}^{3} d t+\eta A\left(\frac{4 f Z}{D}\right)^{3 / 2}\left(\frac{D}{4 f c t}\right)\left(\frac{\partial T}{\partial p}\right)_{V} \rho C_{p}
$$

in which each term is dimensionless. To estimate the size of each term, let us take $\eta=1, n=1, \rho=150 \mathrm{~kg} \cdot \mathrm{m}^{-3}, C_{\mathrm{p}}=2500 \mathrm{~J} \cdot \mathrm{kg}^{-1} \cdot \mathrm{K}^{-1}, \Delta T=1 \mathrm{~K}, c=250 \mathrm{~m} \cdot \mathrm{s}^{-1}$, and $\left(\frac{\partial T}{\partial p}\right)_{V}=2 \mathrm{~K} / \mathrm{MPa}$. First we write Eq. (28) as

$$
\frac{C_{p} \Delta T}{c^{2}}=\frac{1}{2}\left(\frac{4 f X^{3} t}{D c^{2}}\right)+A\left(\frac{\partial T}{\partial p}\right)_{V} \rho C_{p}\left(\frac{4 f X^{3} t}{D c^{2}}\right)^{1 / 2}
$$

which is a quadratic equation for the unknown $\left(4 f X^{3} t / D c^{2}\right)^{1 / 2}$. The coefficients in descending order are $1 / 2,0.5111$, and 0.0400 . With coefficients of this order, the first term on the right is much smaller than the second, and the root of Eq. (29) can be written approximately as

$$
\left(\frac{4 f X^{3} t}{D c^{2}}\right)^{1 / 2}=\left[\left(\frac{\partial p}{\partial T}\right)_{V} \Delta T\right] / A \rho c^{2}
$$

When $n \neq 1,(\mathrm{Eq} .30 \mathrm{a})$ is equivalent to 


$$
\left(\frac{4 f Z}{D}\right)^{3 / 2} \frac{D}{4 f c t}=\left[\left(\frac{\partial p}{\partial T}\right)_{V} \Delta T\right] / A \rho c^{2}
$$

According to this analysis, the onset of TEQ is caused by compression of the fluid element at the piston, not by friction.

\subsubsection{Time at Which Entire Conductor Goes Normal}

Section 4.6.1 gives the time for the onset of THQ; that is, the time at which the fluid element adjacent to the piston reaches $T_{c s}$. In this 'ection we try to find the time at which the fluid elements at the far end of the conductor reach $T_{c s}$, that is, the time at which the entire conductor becomes normal.

For the frictional contribution we again start with Eqs. (25) and (26), but with $\dot{Z}$ replaced by $v(L, t)$, where $L$ is the half-length of the conductor (the normal zone is assumed to start in the middle). Now it can be shown by the methods outlined in refs. 6 and 12 that, for large $X$, the solutions $y(x)$ of Eqs. (13) and (14) are asymptotic to $6 / x^{2}$ irrespective of the values of $\alpha, \beta$, and $n X$. [The reader may verify by substitution that $6 / x^{2}$ does in fact satisfy Eq. (13) exactly.] With this asymptotic form, Eq. (15) becomes

$$
\begin{aligned}
v(L, t) & =\eta^{2} 6 t / L^{2} \quad \text { (special units) } \\
& =\eta^{2} 6 c\left(\frac{c t}{L}\right)\left(\frac{D}{4 f L}\right) \quad \text { (ordinary units) }
\end{aligned}
$$

Then

$$
W=\eta^{6} \cdot \frac{27}{16} \frac{D^{2} c^{6} t^{4}}{f^{2} L^{6}}
$$

There is no compressive contribution at the ends of the channel because there is no pressure rise there. Equation (32) can be written in the convenient form

$$
\frac{c t}{D}=\eta^{-3 / 2}\left(\frac{16 f^{2} C_{p} \Delta T}{27 c^{2}}\right)^{1 / 4}\left(\frac{L}{D}\right)^{3 / 2}
$$

involving only dimensionless quantities.

In addition to the condition of validity on the time that arises from Eq. (21b), there is another condition: namely, that which permits use of the asymptotic form (31) for $v(L, t)$. Since $v(L, t)$ must be much less than $\dot{Z}$ at the time given by Eq. (33), this condition of validity is

$$
\frac{\dot{Z}}{c} \gg 2\left(\frac{3 C_{p} \Delta T}{c^{2}}\right)^{1 / 4}\left(\frac{D}{4 f I}\right)^{1 / 2} \text {. }
$$


The independence of the estimate (33) of $n$ and $X$ means that the simplification of imagining the cold helium to be driven by an external piston is not as drastic as we might have thought at first.

Equation (33) is based on the assumption that the piston does not move a substantial fraction of the conductor length $L$ during the time $t$ it takes for the fluid element at the far end of the conductor to reach the current-sharing temperature $T_{c s}$. Then the conductor length $L$ gives the distance of that distal fluid element from the piston and is the correct distance to use in the asymptotic law (31) for the How velocity. But in actual fact, the constancy of the length $L$ is not a good assumption for the following reason. As fluid elements reach $T_{c s}$ and normalize the conductor next to them, they begin to absorb Joule power from the conductor and expand. Thus, it seems that the piston pushing the cold helium has moved downstream, and its distance to the distal fluid element seems smaller. Since the velocity of a fluid element at any given time is larger the closer it is to the piston [by roughly the square of the distance, according to the asymptotic law (31)], most of the heat that brings the distal fluid element to $T_{c}$, is absorbed when the piston is fairly close to it. Thus, the effective length $L$ to use in Eq. (33) should be smaller than the actual channel length; Eq. (33) should give an overestimate of the time $t$ for THQ to finish when the actual length of the channel is used for $L$. Only detailed numerical calculations or comparison with experiment can determine the precise factor of reduction to apply to the geometric length $L$.

\subsubsection{Thermal Hydraulic Quenchback in the SSC Dipoles}

In the SSC dipoles, the distance $L$ is not the half-length of the conductor but rather the distance from the edge of the initial normal zone to the next voltage tap. Beyond that voltage tap, the conductor extends many times the length $L$. Thus, we cannot ignore the compressive contribution to the heating as we did in Sect. 4.6.2, where $L$ marked the positive of the open end of the conductor.

The pressure at position $L$ is given in special units by

$$
p=\frac{1}{2} \int_{L}^{\infty} v^{2} d \zeta,
$$

where $v$ is now given by the asymptotic form $v=6 t / \zeta^{2}$. The integration yields

$$
\begin{aligned}
p & =\frac{6 t^{2}}{Z^{3}} \quad \text { (special units) } \\
& =6 \rho c^{2}\left(\frac{c t}{L}\right)^{2}\left(\frac{D}{4 f L}\right) \quad \text { (ordinary units). }
\end{aligned}
$$


A short calculation then shows that the analogue of Eq. (29) is

$$
\frac{C_{p} \Delta T}{c^{2}}=\frac{27}{16}\left(\frac{c^{2} D t^{2}}{f L^{3}}\right)^{2}+\frac{3}{2} \rho C_{p}\left(\frac{\partial T}{\partial p}\right)_{V}\left(\frac{c^{2} D t^{2}}{f L^{3}}\right) .
$$

Again, the first term on the right-hand side is much smaller than the second, and so Eq. (38) gives

$$
\frac{c t}{D}=\left[\frac{2 f \Delta T(\partial p / \partial T)_{0}}{3 \rho c^{2}}\right]^{1 / 2}\left(\frac{L}{D}\right)^{3 / 2}
$$

Again, the effective length $L$ should be smaller than the actual length.

\section{COMPARISON OF DATA ON SSC DIPOLES WITH THE SIMILARITY THEORY}

Figure 2 is a schematic diagram of the SSC dipoles. Most of the helium inventory is contained in the thin channel between the bore tube and the inner layer of conductors, but the cable itself contains about 13 vol $\%$ of helium that is enclosed by the insulation. The tight confinement of these helium volumes may cause either to expand longitudinally down the channel as described in Sect. 4 and lead to THQ.

If the quench were propagated by THQ in the volume between the bore tube and the conductors as singgested in ref. 2, we would expect all turns in a quadrant to go normal almost simultaneously, because THQ should begin all across the belium channel almost immediately after establishment of a normal zone in one of the conductors. The evidence, however, belies this expectation: Fig. 5 of ref. 13 shows a quench propagating transversely from turn to turn at regular intervals of roughly 15 ms. This can only be due to the thermal delay introduced by the turn-to-turn insulation. It therefore seems doubtful that quenches are being propagated by THQ in the space between the bore tube and the conductor.

This argument makes it seem highly likely that quenches are propagated by THQ in the interstitial helium, that is, the helium confined in the cable itself. To test this hypothesis further, we analyzed a quench in turn 13 of magnet DD0010, for which extensive data are given in ref. 13. According to this reference, the quench starts $7.2 \mathrm{~m}$ from the return end of the straight secticas and travels in both directions (two fronts) with a velocity of $102 \mathrm{~m} / \mathrm{s}$. As noted in ref. 13, a velocity of only $28 \mathrm{~m} / \mathrm{s}$ is expected from the classical conduction theory.

Table 2 gives characteristics of the SSC dipole conductor, ambient belium, and quench. The only quantity missing from Table 2 is the friction factor. Data on 
ORNL-DWG 90-2741 FED

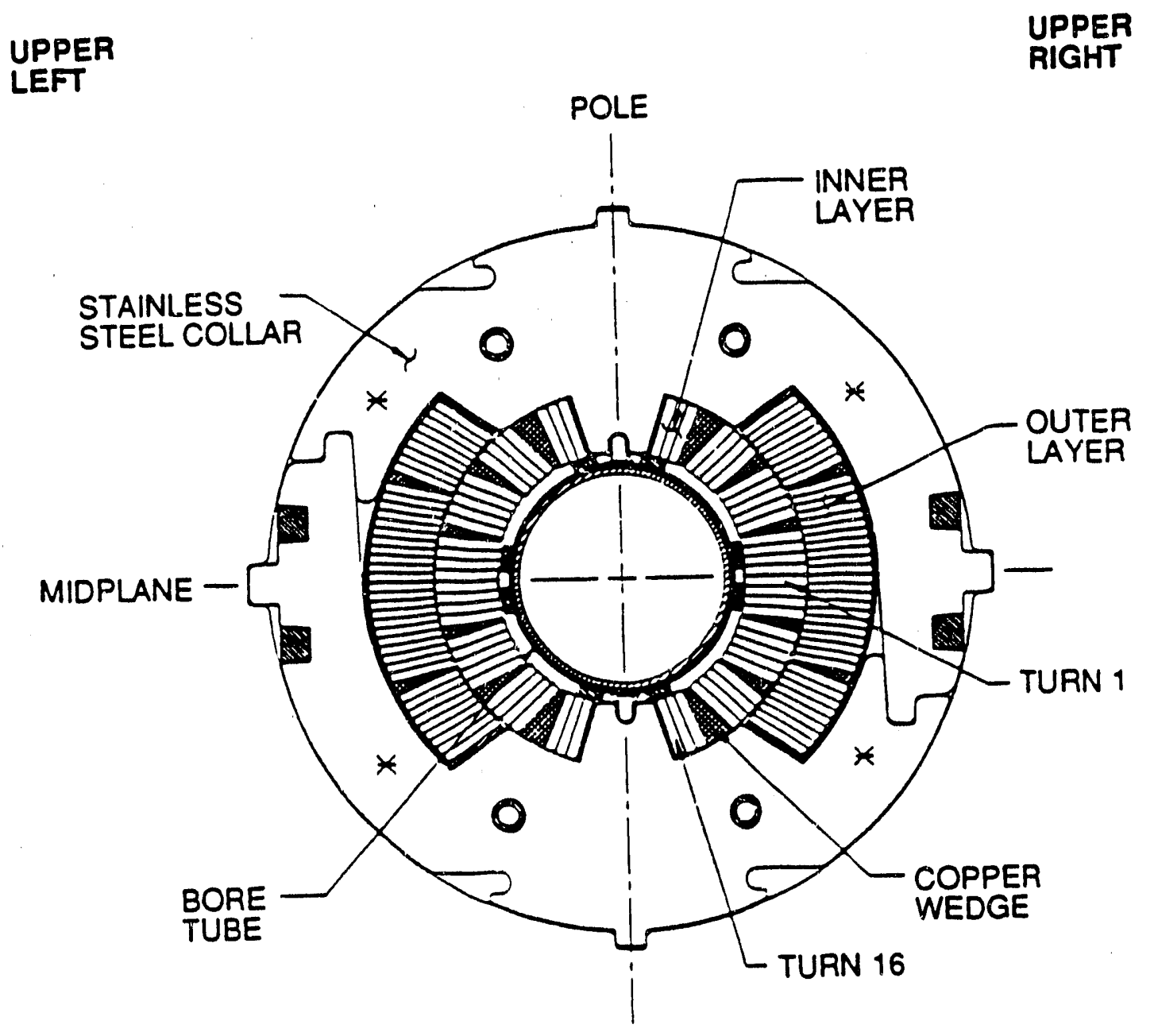

Fig. 2. A schemati cross section of the SSC dipoles. 
Table 2. SSC dipole quench, conductor, and ambient helium characteristics

Conductor

Hydraulic diameter $D, \mathrm{~mm}$

$\mathrm{Cu} / \mathrm{SC}$ ratio

Strand diameter, $\mathrm{mm}$

Number of strands 23

Cable dimensions, mm

Ambient heliuma

Bath (ambient) temperature $T_{b}, \mathrm{~K}$

Current-sharing threshold temperature $T_{c s}, \mathrm{~K}$

$\Delta T\left(=T_{c s}-T_{b}\right), \mathrm{K}$

Critical temperature $T_{c}, \mathrm{~K}$

Pressure $p, \mathrm{MPa}$

0.4

Density $\rho_{d}, \mathrm{~kg} \cdot \mathrm{m}^{-3}$

$\mu, \mu \mathrm{Pa} \cdot \mathrm{s}$

$\beta, \mathrm{K}^{-1}$

0.1176

Constart-pressure specific heat $C_{p}, \mathrm{~J} \cdot \mathrm{kg}^{-1} \cdot \mathrm{K}$

$\left(\partial_{p} / \partial T\right)_{V}, \mathrm{MPa} \cdot \mathrm{K}^{-1}$

Speed of sound $c, \mathrm{~m} / \mathrm{s}$

Quesch

Current $I, A$

Dimensionless current $i\left(=I / I_{c}\right)$

0.85

Peak magnetic field $B_{\text {peak }}, T$

Time to one end $t_{1}$, ms

Time to the other end $t_{2}$, ms

84.0

Distance to one end $L_{1}, \mathrm{~m}$

Distance to the other end $L_{2}, \mathrm{~m}$

8.52

a. Thermodynamic properties evaluated at $T=\left(T_{c s}+T_{b}\right) / 2 \approx 4.5 \mathrm{~K}, p=0.4 \mathrm{MPa}$.

friction factors in cables have been presented by Lue, Miller, and Lottin ${ }^{14}$ and by Daugherty, Huang, and van Sciver. ${ }^{15}$ The data cover a range of wire diameters from $0.56 \mathrm{~mm}$ to $1.06 \mathrm{~mm}$, void fractions from $35 \%$ to $60 \%$, and Reynolds numbers up to about $10^{4}$. Altogether, Lue et al. reported data at room and nitrogen temperatures 
for nine samples utilizing four different cabling patterns. At the highest Reynolds number $\left(10^{4}\right)$ they found the Fanning friction factor to be about $0.02 \pm 25 \%$. Daugherty et al. studied two conductors in the temperature range from 3 to $7 \mathrm{~K}$. For one of them they also found a friction factor of 0.02 for Reynolds numbers exceeding 5000 , but for the other they found a friction factor ten times smaller. It is diffcult to see what is different about the cable with the much smaller friction factor. Subsequently we choose the larger value, $f=0.02$.

Using these values we can find the effective channel length $L$ to use in Eq. (4.39) as explained in Sect. 4. The result is $L_{\text {eff }} / L=0.63$ for both fronts, so that an empirical factor of 0.50 must be pluced before Eq. (4.39). In light of the argument at the end of Sect. 4, this is not an unreasonable result.

How long does it take for THQ to begin? To answer this question using Eq. (4.30), we must first determine the initial rate of expansion of the normal zone, i.e., the initial piston velocity. We cars do this with the following equation, taken from ref. 16 , which gives the normal zone expansion velocity $U$ for early times:

$$
\frac{U}{c}=0.600\left(\frac{D}{f c t}\right)^{1 / 3}\left(\frac{B q t}{C_{p}}\right)^{2 / 3} .
$$

Here $q$ is the specific Joule power transferred from the fully normal conductor to the helium (W. $\mathrm{kg}^{-1}$ ). Then Eq. (1) yields $U=U_{0} t^{1 / 3}, U_{0}=165 \mathrm{~m} \cdot \mathrm{s}^{4 / 3}$. If we insert this into Eq. (4.30b) along with $A=0.839(n=4 / 3)$, we find that $t=0.158 \mathrm{~ms}$; that is, thermal bydraulic quenchback begins immediately for all intents and purposes. This is because of the truly enormous Joule heating of the interstitial helium of $9.7 \mathrm{~kW} \cdot \mathrm{g}^{-1}$.

According to Eq. (4.39) the average propagation velocity $L / t$ depends on the fraction of critical current $i$ as $(1-i)^{-1 / 2}$; this dependence arises only through the dependence of $T$ on $i$. Figure 3 shows the measured propagation velocity for six magnets plotted vs $i$ and a curve proportional to $(1-i)^{-1 / 2}$ and normalized to fit well over the entire range. The good agreement implies that the ratio $L_{\text {eff }} / L$ depends only slightly, if at all, on $i$.

\section{DISCUSSION AND RECOMMENDATIONS}

The hydrodynamic theory of Sect. 4 cannot be compared in detail with the experimental results because of the appearance of the undetermined length $L_{\text {eff }}$. 


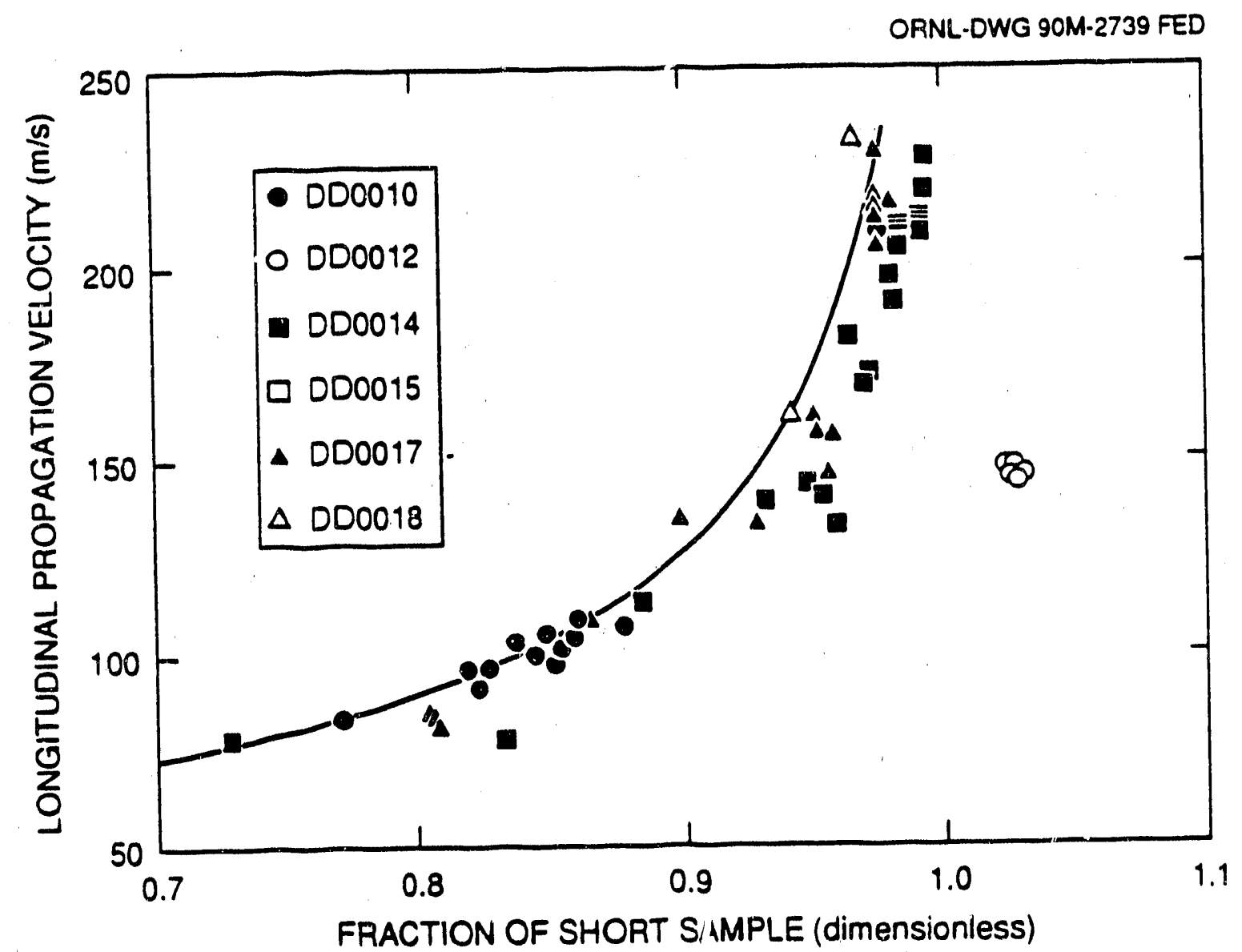

Fig. 3. A plot of the longitudinal propagation velocity for six magnets plotted versus the fraction of short sample critical current $i$. The curve is proportional $(1-i)^{-1 / 2}$ and has been normalized to fit well over the entire range. 
Nevertheless, with the reasonable value $L_{\text {eff }} / L=0.63$, this theory can account for the high propagation velocities measured in the SSC dipoles. The classical conduction theory, on the other hand, can never account for these high velocities.

The validity of the formulas (4.30) and (4.33) can be tested by romparing them with the numerical results of Luongo et al. ${ }^{1}$ and with some recent experimental results of Ando et al. ${ }^{17}$ Luongo's Fig. 5 (shown here as Fig. 4) shows the location of the normal front for a particular conductor as a function of time. In interpreting these results, a caution must be applied. Luongo begins his computation by turning on a hypothetical heater that takes a short time to heat the conductor to the current sharing threshold. The instant at which this happens can be inferred by noting when the normal front begins to move, about $0.075 \mathrm{~s}$ in Fig. 4 . So $75 \mathrm{~ms}$ on the abscissa scale in Fig. 4 should be taken as the zero of elapsed time. The entire sampie goes normal at an elapsed time of $0.25 \mathrm{~s}$, so the average velocity of propagation is $91 \mathrm{~m} / \mathrm{s}$. Equations (4.30), (5.1), and (4.33) give $0.11 \mathrm{~s}$ as the onset time and $0.43 \mathrm{~s}$ as the time at which the entire sample becomes normal. The latter time is an upper bound, as mentioned before, and from it we can calculate a lower bound to the average velocity of propagation, namely, $58 \mathrm{~m} / \mathrm{s}$. If we use the factor of 0.63 found above to correct the length $L$ of the channel, we find that the entire sample goes normal at an elapsed time of $0.215 \mathrm{~s}$, which corresponds to an average velocity of $116 \mathrm{~m} / \mathrm{s}$. Although this rather good agreement may be fortuitous, it does appear that the analytic theory of the present paper is consistent with the results of the numerical calculations.

We cannot perform such a detailed analysis of the data of Ando et al., ${ }^{17}$ because the condition (4.34) for the applicability of Eq. (4.33) is not met. Equation (4.34) requires the piston velocity to be $\geq 8 \mathrm{~m} / \mathrm{s}$, and such large values of the velocity are not achieved in Ando's experiment. Equation (4.30a) predicts that the quantity $X^{3} t$ should be about $1.4 \mathrm{~m}^{3} \cdot \mathrm{s}^{-2}$ when $I=1.9 \mathrm{kA}$. We see that the data in Fig. 5 then require the onset time to be about $1 \mathrm{~s}$. Since the data are not marked by any sudden acceleration in the motion of the normal front, it is hard to say categorically that THQ is taking place. If we place our faith in the theory and say that it is, then we should expect a smoothly accelerating normal front to be characteristic of a conductor undergoing THQ. Preliminary experiments recently carried out at ORNL by Lue and Schwenterly (see Appendix I) give results much like Ando's, namely, smoothly accelerating propagation velocities averaging several meters per second. It is a little dangerous, however, to extrapolate this experimentally observed behavior directly to the SSC dipoles because of the hundred-fold difference in Joule power 


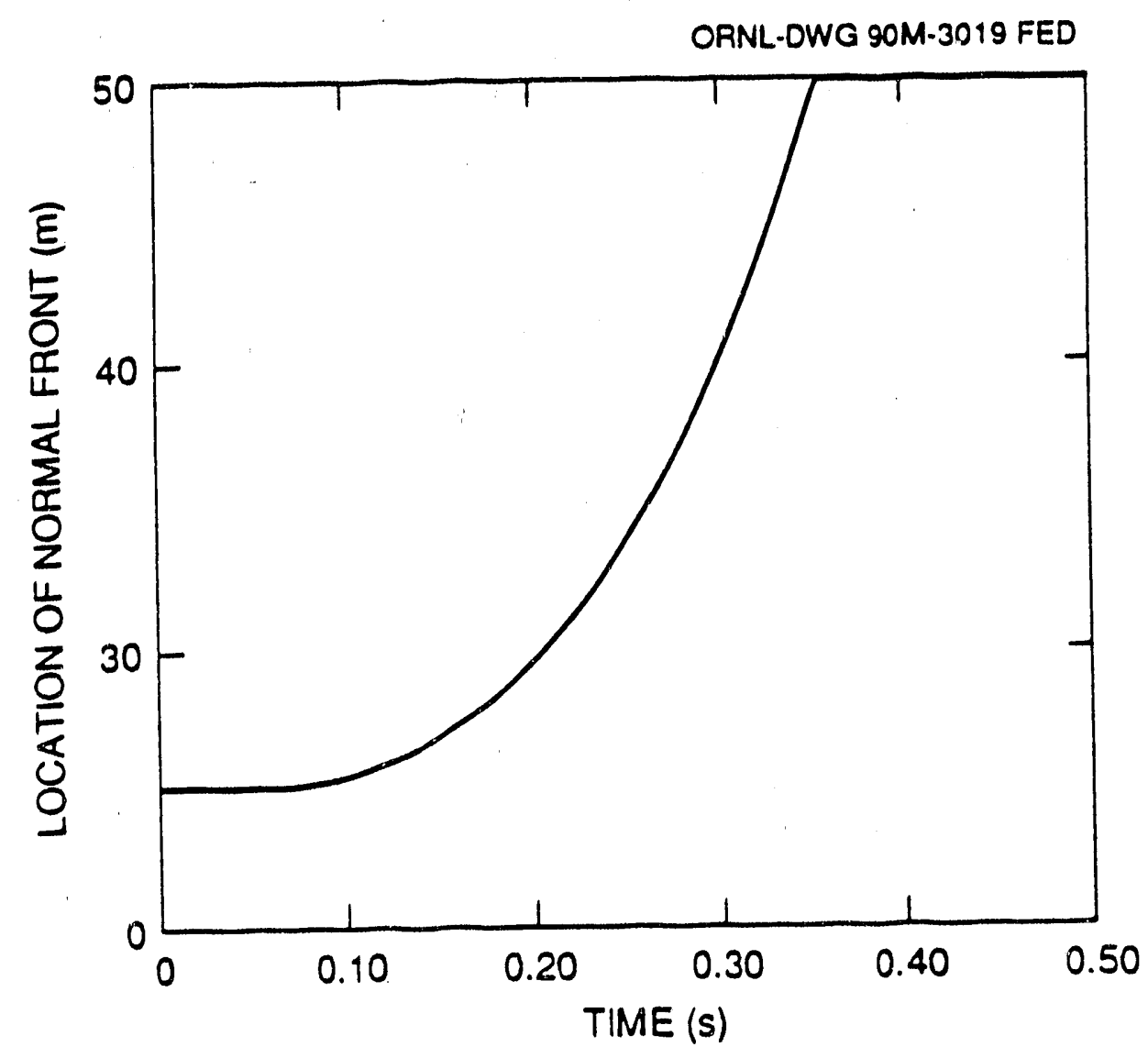

Fig. 4. Location of the normal front $(L=50 \mathrm{~m}$, initial normal zone covers half of the section, $T_{0}=4.2 \mathrm{~K}$ ). Source: C. A. Luongo et al., "Thermal Hydraulic Simulation of Helium Expansion from a Cable-in-Conduit Superconductor," IEEE Trans. Magn. 25, 1589-95 (1989). 


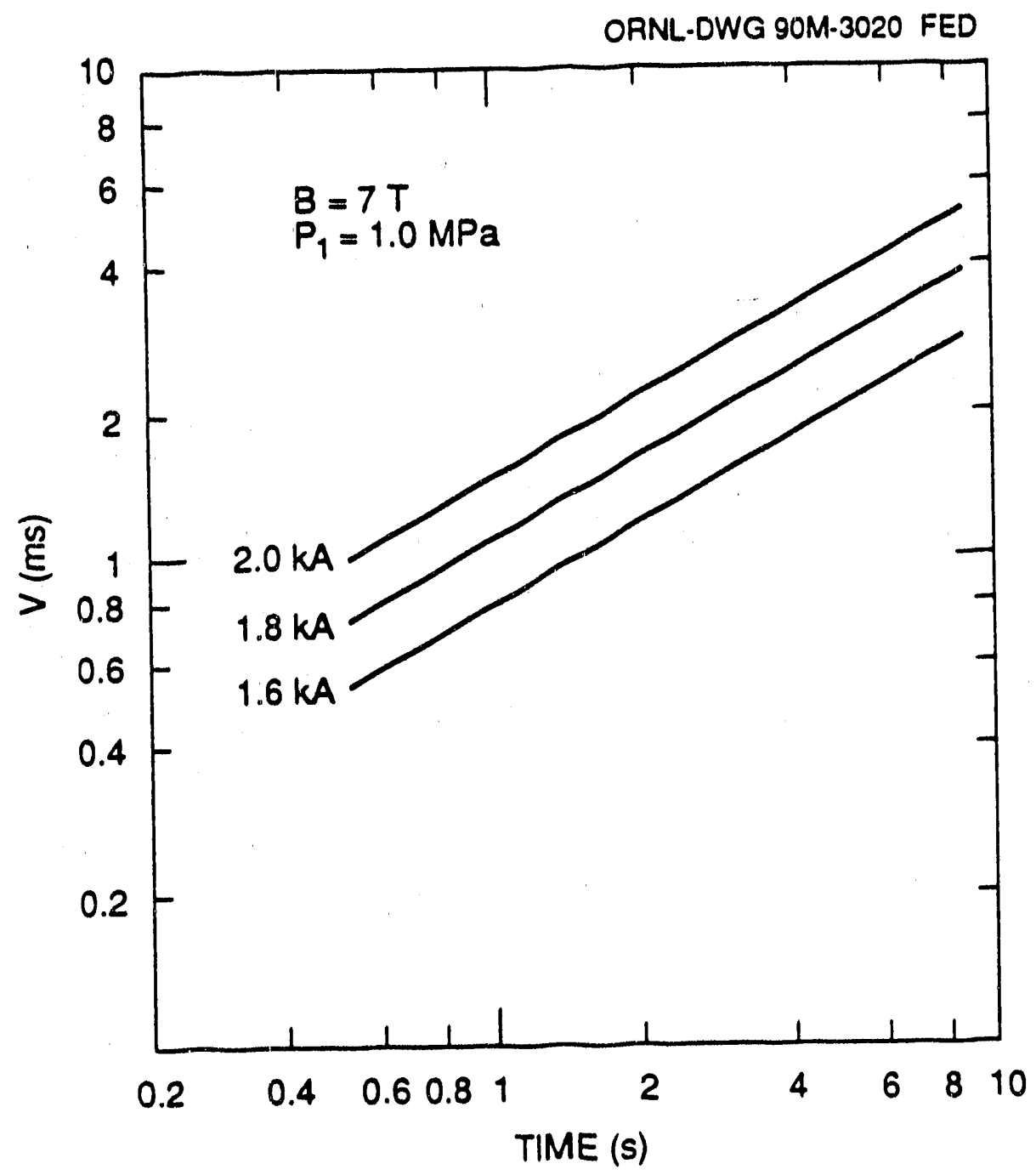

Fig. 5. Propagation velocity for the normal front $V$ vs the elapsed time $t$ for 1.6, 1.8, and $2 \mathrm{kA}$ at $7 \mathrm{~T}$ and $1 \mathrm{MPa}$. Source: T. Ando et al., "Propagation Velocity of the Normal Zone in a Cable-in-Conduit Superconductor," presented at the 1989 Cryogenic Engineering Conference, Los Angeles, July 24-28, 1989. 
density between the SSC dipoles and the experiments of Ando et al. About all we can say is that the experiments of Ando et al. and Lue et al. do not contradict the theory of this paper.

To further test our hypothesis that the hydrodynamic explanation is the correct one, we seem compelled to undertake additional experiments with the SSC dipoles. Perhaps the most revealing experiment would be to pump away the helium and quench the magnet dry. If the hydrodynamic explanation is correct, then the propagation velocity should fall to the lower values predicted by the conduction theory. When this proposed experiment was discussed at the August 16 quench workshop, some of the participants pointed out that it would be necessary to keep the current leads and the splices wet with helium. Since the leads and splices are all located at one end of the magnet, the experiment could still be carried out if the magnet were tipped or suspended with the lead-splice end low. This was deemed too difficult to be worthwhile, and several participants suggested testing a 17 -m-long sample conductor with and without interstitial helium in the bore of one of the dipoles. If the bore tube is to contain helium, then the sample conductor will have to be encased in an a jacket impervious to belium when it is run dry.

If this first experiment were to sustain the hydrodynamic explanation, the next experiment to try would be to remove the bore tube. If, as suggested in ref. 2, the helium between the conductor and the bore tube were responsible for thermal hydraulic quenchback, the velocity of propagation would again fall. On the other hand, if the interstitial helium were responsible for thermal hydraulic quenchback, removing the bore tube would make no difference. Some participants in the August 16 workshop pointed out that the annulus between the bore tube and the edge of the conductor would be much wider in the so-called 5-cm magnets than in the 4-cm magnets. If the annular helium is responsibie for the rapid propagation observed, then the velocity should be substantially lower in the 5-cm magnets than in the 4-cm magnets. If the interstitial helium is responsible, then there should be no difference. 


\section{REFERENCES}

1. C. A. Luongo et al., "Thermal Hydraulic Simulation of Helium Expulsion from a Cable-in-Conduit Conductor," IE, TE Trans. Magn. 25, 1589-1595 (1989).

2. A. Devred et al., "Development of Spontaneous Quenches in Full-Length SSC R\&D Dipoles," presented at the 1989 Particle Accelerator Conference, Chicago, March 20-23, 1989.

3. Lawrence Dresner, "Thermal Expulsion of Helium From a, Quenching Cablein-Conduit Conductor," pp. 618-21 in Proceedings of the Ninth Symposium on the Engineering Problems of inusion Research, Chicago, 1981, IEEE, New York, 1981.

4. Lawrence Dresner, "Quench Detection by Fluid Dynamic Means in Cable-inConduit Superconductors," Adv. Cryo. Eng. 33, 167-74 (1988).

5. Lawrence Dresner, "Quench Pressure, Thermal Expulsion, and Normal Zone Propagation in Internally Cooled Superconductors," IEEE Trans. Magn. 25 (2), 1710-12 (1989).

6. Lawrence Dresner, Similarity Solutions of Nonlinear Partial Differential Equations, Pitman Publishing Inc., Marshfield, Mass., October 1983.

7. L. Dresner, "Analytic Solution for the Propagation Velocity in Superconducting Composites," IEEE Trans. Magn. MAG-15 (1), 328 (1979).

8. L. Dresner, Normal Zone Propagation in Thermally Insulated Superconductors," Adv. Cryo. Eng. 26, 647-53 (1980).

9. John Peoples, "Status of the SSC Superconducting Magnet Program," IEEE Trans. Magn. 25 (2), 1444-50 (1989).

10. S. A. Elrod, J. R. Miller, and L. Dresner, "The Specific Heat of NbTi from 0 to 7 T Between 4.2 and $20 \mathrm{~K},{ }^{n}$ Adv. Cryo. Eng. 28, 601-10 (1982).

11. R. P. Reed and A. F. Clark (eds.), Materials at Low Ternperatures, American Society for Metals, Metals Park, Ohio, 1983.

12. Lawrence Dresner, Asymptotic Behavior of Solutions of Diffusion-Like Partial Differential Equations Invariant to a Family of Affine Groups, ORNL/TM11559, Martin Marietta Energy Systems, Oak Ridge National Laboratory, July 1990.

13. A. Devred et al., Quench Localization in Full-Length SSC R\&D Dipoles, SSC214, April 1989.

14. J. W. Lue, J. R. Miller, and J. C. Lottin, "Pressure Drop Measurement on Forced-Flow Cable Conductors," IEEE Trans. Magn. 15 (1), 53-55 (1979). 
15. M. A. Daugherty, Y. Huang, and S. W. van Sciver, "Pressure Drop Measurement on Supercritical-Helium-Cooled Cable-in-Conduit Conductors," IEEE Trans. Magn. 25 (2), 1512-15 (1989).

16. Lawrence Dresner, "The Growth of Normal Zones in Cable-in Conduit Superconductor," pp. 2040-43 in Proceedings of the Tenth Symposium on Fusion Engineering, Philadelphia, 1989, IEEE, New York, 1983.

17. T. Ando, M. Nishi, T. Kato, J. Yoshida, N. Itoh, and S. Shimamoto, "Propagation Velocity of the Normal Zone in a Cable-in-Conduit Conductor," presented at the 1989 Cryogenic Engineering Couference, Los Angeles, July 24-28, 1989. 


\section{LIST OF SYMBOLS}

(Equation numbers refer to Sect. 4)

A numerical constant defined in Eq. (19) and calculable from Eq. (24), dimensionless

$B$ volume coefficient of theimal expansion, $\frac{1}{\nabla}\left(\frac{\partial V}{\partial T}\right)_{p}, \mathrm{~K}^{-1}$

c speed of sound, $m / s$

$C_{p} \quad$ constant-pressure specific heat, $\mathrm{J} \cdot \mathrm{kg}^{-1} \cdot \mathrm{K}^{-1}$

$D$ hydraulic diameter, $\mathrm{m}$

e specific internal energy, $\mathrm{J} \cdot \mathrm{kg}^{-1}$

$f \quad$ Fanning friction factor, dimensionless

$F \quad$ fractional force per unit mass $\left(=2 f v^{2} / D\right)$

$H$ heat transfer coefficient

I current, A

$I_{c} \quad$ critical current, A

$J_{c}$ overall current density in the composite, $\mathrm{A} / \mathrm{m}^{2}$

$k$ in Sect. 3, thermal conductivity; in Sect 4, function of time defined in Eq. (15)

$m$ numerical constant defined in Eq. (5b), dimensionless

$n$ power of time describing displacement $Z$ of the piston, dimensionless

$p$ pressure, $\mathrm{Pa}$

$P \quad$ wetted perimeter, $m$

$Q \quad$ power density entering the helium, $\mathrm{W} \cdot \mathrm{m}^{-3}$

$s \quad$ specific entropy, $\mathrm{J} \cdot \mathrm{kg}^{-1} \cdot \mathrm{K}^{-1}$

$\mathrm{S} \quad$ volumetric heat capacity $\left(=\rho C_{\mathrm{p}}\right), \mathrm{J} \cdot \mathrm{m}^{-3} \cdot \mathrm{K}^{-1}$

$t$ time, $s$

$T$ temperature, $\mathrm{K}$

$T_{b} \quad$ bath (ambient) temperature, $\mathrm{K}$

$T_{c} \quad$ critical temperature, $\mathrm{K}$

$T_{c 0} \quad$ critical temperature at zero field, $\mathrm{K}$

$T_{c}$, current-sharing threshold temperature, $\mathrm{K}$

$\Delta T \quad T_{c s}-T_{b}, \mathrm{~K}$

$v \quad$ flow velocity, $\mathrm{m} / \mathrm{s}$

$v$ fiducial velocity, $\mathrm{m} / \mathrm{s}$

$W \quad$ specific frictional work [see Eq. (26)], J $\mathrm{kg}^{-1}$

$x \quad \xi / t^{1 / \beta}$, similarity variable 
$X \quad$ coefficient in power law $Z=X t^{n}$ for the piston displacement

$y \quad$ function of $x$ defined in Eq. (12) and calculable from Eqs. (13) and (14)

$z \quad$ distance coordinate, $m$

$Z$ displacement of the piston, $m$

$\alpha \quad$ parameter labeling groups of the family (10)

$\beta \quad$ parameter labeling groups of the family (10)

$\zeta \quad$ distance measured from the piston $[=z-Z(t)], m$

$\eta \quad$ auxiliary variable defined in Eq. (21c)

$\lambda$ parameter labeling individual transformations of the group (10)

$\mu \quad$ parameter labeling individual transformations of the group (18)

$\xi \quad$ auxiliary variable defined in Eq. (21b)

$\rho$ density, $\mathrm{kg} \cdot \mathrm{m}^{-3}$

$\rho_{e} \quad$ resistivity of copper, $\Omega \cdot \mathrm{cm}$

$\tau \quad$ specific volume, $1 / \rho, \mathrm{m}^{-3} \cdot \mathrm{kg}$ 
Appendix 1

QUENCH PROPAGATION IN A CABLE-IN-CONDUIT FORCE-COOLED SUPERCONDUCTOR-PRELIMINARY RESULTS 


\author{
J. W. Lue, S. W. Schwenterly, L. Dresner, and M. S. Lubell \\ Oal: Ridge National Laboratory \\ P.O. Box 2009
}

Oak Ridge, TN 37831-8040

\section{Abstract}

Cable-in-conduit force-cooled superconductor is being considered for use in a superconducting magnetic eners storage (SMES) system. The quench behavior of such a conductor plays a very important role in the protection of this system and of other magnets having similar cooling environments. In particular, the existence of the thermohydraulic quenchback effect predicted recently by numerical ansiysis and theoretical calculation has been investigated experimentally. The test sample consists of a 50 -m-long single triplex NbTi superconductor enclosed in a staicless steel conduit. Heaters 0.2 to $8 \mathrm{~m}$ long are provided both at the center and at one end of the sample, and the beated end can be closed off to simulate quenching centered in a 100-mlong conductor. The queach behavior of the conductor (e.g., the propagation velocity and the temperature profile) was measured as a function of initial normal zone length, conductor current density, helium temperature, etc. This paper reports the test results and the comparison with the predictions.

\section{Introduction}

In a cabie-in-conduit force-cooled superconducting magnet, the coolant is limited to the interstitial belium inside the conduit. It cannot be replenished fast enough to provide steadystate heat traosfer when the conductor goes normal. Hence the quench behavior of the conductor depends strongly on the thermal bydraulica of the coolant. A few papers have been devoted to the study of the properties of a quenching cable-in-conduit superconductor, such as quench presure,' thermal expulioen, hot-spot temperature, ${ }^{3}$ and propagation velocity."

In a study of using cable-in-conduit superconductor for a superconducting magnetie energy storage (SMES) system, it was found in a numerical simulation that a phenomenon called thermal hydraulic quenchback (THQ) ${ }^{3}$ may occur in such a coaductor. Comprescion of and friction on the belium far from a normal zone, resulting from the expansion of the beated helium in the normal zone, may raise the temperature of the helium above the current-sharing threshold. The strands in contact with it then become normal, and a jump in normal zone propagation velocity follows. This phenomenon was confirmed recently in an analysis based on similarity solutions. ${ }^{6}$

Very iurge propagation velocities $(100-200 \mathrm{~m} / \mathrm{s})$ obeerved in the full-length Superconducting Super Collider (SSC) test dipoles might be the result of THQ. On the other hand, the propagation velocities reported in Refs. 3 and 4 were only a few meters per second or less, and no appreciable jump in velocity was observed. The existence of THQ and the resulting fart normal zone propagation will have a strong influence on the quench preanure and hot-spot temperature, and thus on the protection, of a magnet made of cable-in-conduit conductor or with similar confined cooling channels. An experiment was conducted to mearure the quench propagation velocity in a cable-in-conduit conductor and to verify the existence of THQ and its dependeace on various operating parameters.

\footnotetext{
* Research sponsored by the Defense Nuclear Agency under Interagency Agreement No. 0046C082A1 under Martin Marietta Enere Syent Inc.; contract DE-AC05-84OR21400 with the U.S. Department of Energy.
}

Manuscript received September 24, 1990.

\section{Experimental Setup}

The experimental setup consinted of a 30-m-lons sample mounted inside a recuum chamber. A croatat supplied supercritical helium to the sample and housed the superconducting buses and the vapor-cooled leads. Experimental data were taken by a dat acquipition system that allowed some real-time monitoring and data retrieval and plotting at a later time.

\section{Sample}

The 50-m-long sample is made of a triplex of NbTi superconducting wires. The triplex is enclosed inside 3.16-mm-ID stainleas steel tubes. Two sets of five resistive beaters, $0.4 \mathrm{~m}$ to $3 \mathrm{~m}$ long, were installed in the middle of the sample, one set inside the tube and the other on the outside of the tube. The interior heaters were lying in the grooves of the triplex. All heaters were bifilarly wound to reduce inductive signal to the voltage taps. By using different combinations of heaters, the heated zone length could be varied from $0.4 \mathrm{~m}$ to $8 \mathrm{~m}$. Similar pairs of heater sets could be varied trom end of the sample. By closing the belium inlet at this end, quenching centered in a 100-m-long sample could be simulated. Table 1 lists the test conductor data.

Table 1. Sample Description

\begin{tabular}{|c|c|}
\hline 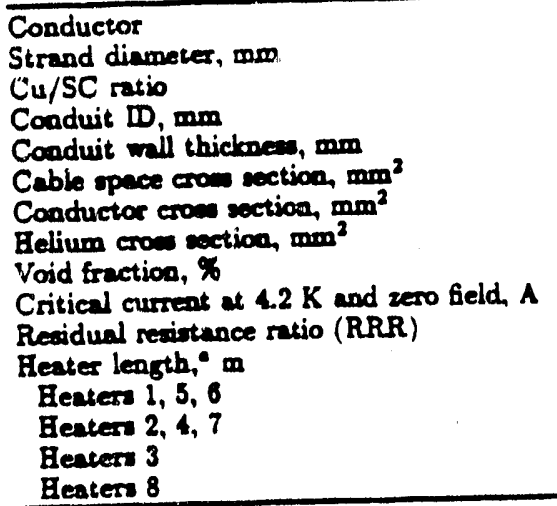 & $\begin{array}{l}\text { NbTi triplex } \\
1.27 \\
5.8: 1 \\
3.16 \\
0.41 \\
7.82 \\
3.96 \\
3.87 \\
49.5 \\
4500 \\
136 \\
3.0 \\
0.8 \\
0.4 \\
0.3\end{array}$ \\
\hline
\end{tabular}

Numerous voltage taps and thermocouples (TCs) were installed along the sample, moot of them adjacent to heaters. Figure 1 is a sloteh of the sample and its instrumentation layout. The sample wa bifilarly wound on a $75-c m-l o n g, 16-\mathrm{cm}$-diam (insulated) stainless steel mandrel.

\section{Cryoutat}

The cryostat was made of a $13-\mathrm{cm}$ stainless ateel can to which the sample mandrel was attached. It was housed inside a $25-\mathrm{cm}$ diam dewar used as a vacuum chamber. Thus, tho sample was in racuum insulation to reduce thermal transfer between adjacent turns. Inside the steel can was a beat exchanger to supply supercritical belium to the sample. A pair $\alpha$ superconducting buses tied to the vapor-cooled leads on the top penetrated the bot tom of the can to feed current to the sample. Au-Fe vs Chromel TCs from the sample also entered the can to a reference junction in the beiium bsith. 


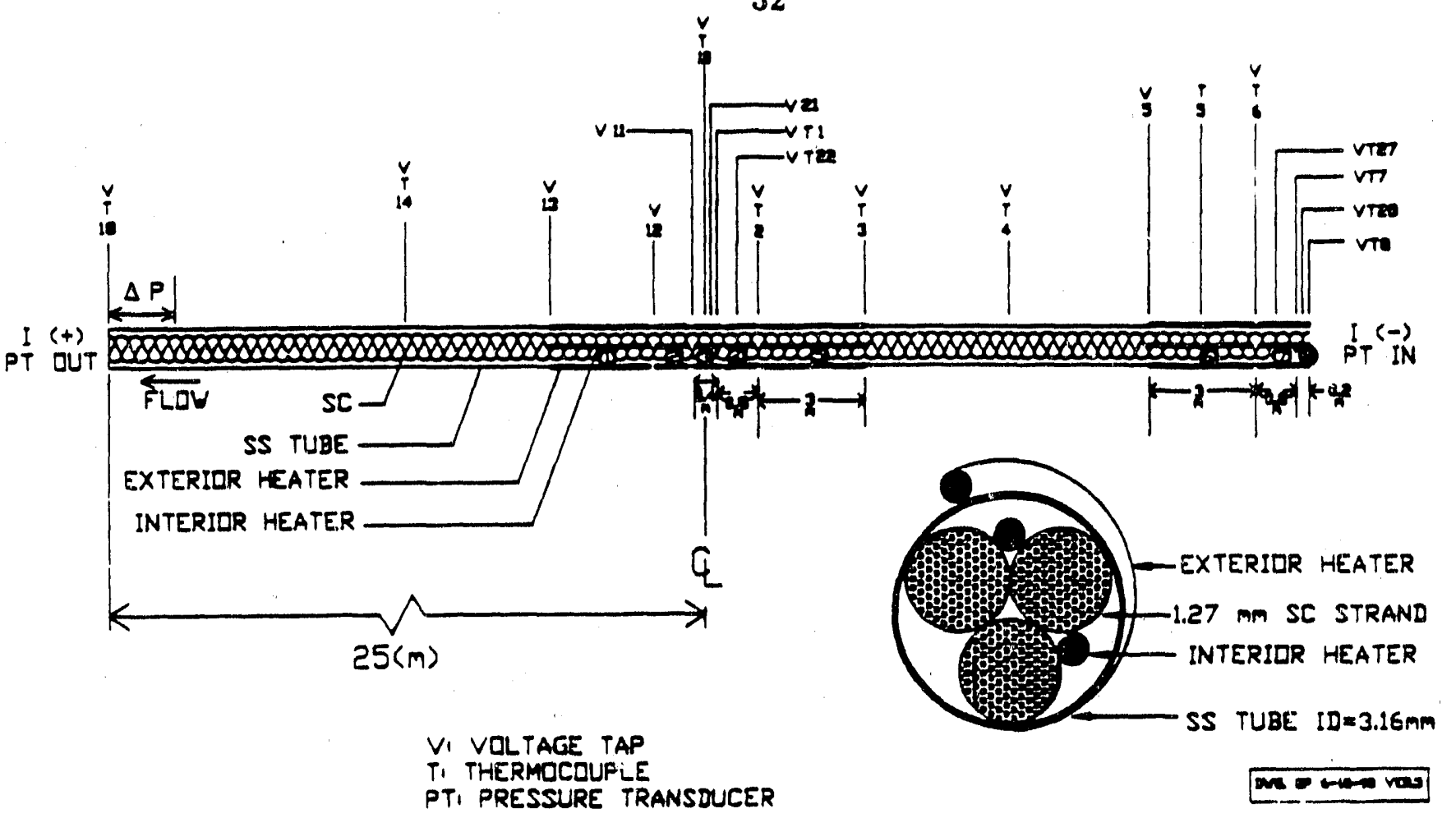

Fig. 1. Tripléx cable-in-conduit sample and its instrumentation layout.

Daca Acquisition System

A computerized data acquisition system was used to acquire and store the tert data. Voltage, temperature, and strain gauge type signals were fed into 64 front end modules. The outputs are transmitted through a CAMAC crate to a microVAX computer. Real-time monitoring of selected signals can also be taken from the output of the froat-end modules. The data uampling rate can be varied for each test shot from 5 Hz to $25,000 \mathrm{~Hz}$.

\section{Test Reruits}

A test shot was initiated by ramping the sample current to a given level, setting the belium fow, and pulsing the beater. The beater trigger pulse also started the data acquisition system. Sample current was turned of to end the shot when the voltage or the TC signal being moxitored reached a specified value. During this series of tests, 21 shots were taken at currents ranging from 200 to 800 A. At $400 \mathrm{~A}$, the curreat density is $101 \mathrm{~A} / \mathrm{mm}^{2}$ over the triplex conductor and $51 \mathrm{~A} / \mathrm{mm}^{2}$ over the cable spece. Table 2 summarizes the conditions $\alpha$ the shots in which good normal zone propagation wa observed. All shots were taken without background field at $4.3 \mathrm{~K}$, and with the beaters in the midpoint of the sample. The teat was halted when current bus burned out.

\section{Voltage Signals}

The voltage taps shown in Fig. I detect voltage signals at the beated zone and alons the conductor. Figure 2 shows the voltage evolution along one side of the conductor for one $400-$ A shot (shot 1007). VT10-01, which covers half of the beated zone, and VTO1-02, which cover the adjacent 20ne, came up immediately after the beater pulse. VTO2-03, which is 0.8 to away, showed voltage $3.3 \mathrm{~s}$ later, indicating that the normal zone passed VTO2. Meanwbile, the voltage in VT1O-01 and VTO1-02

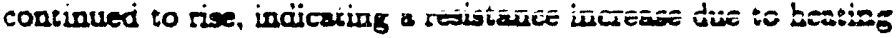

Table 2. Shot Summary

\begin{tabular}{|c|c|c|c|c|c|c|c|}
\hline Shot & Heacer & $\begin{array}{l}\text { Beater } \\
\text { currens } \\
I_{h}(A)\end{array}$ & $\begin{array}{l}\text { Duration } \\
\alpha \text { It on, } \\
n \text { (m) }\end{array}$ & $\begin{array}{l}\text { Duration } \\
\alpha f_{*} \text { on. } \\
r_{0}(s)\end{array}$ & $\begin{array}{l}\text { Final } \\
\text { sample } \\
\text { current } \\
f_{0} \text { (A) }\end{array}$ & $\begin{array}{l}P_{\text {in }} \\
\text { (atm) }\end{array}$ & $\begin{array}{l}\text { Mow } \\
(\mathbf{m} / \mathrm{s})\end{array}$ \\
\hline \multicolumn{8}{|c|}{$400-A$ shoce: } \\
\hline $\begin{array}{l}1008 \\
1007 \\
1008 \\
1017 \\
1018 \\
1022\end{array}$ & $\begin{array}{l}3 \\
3 \\
13 \\
12-14 \\
12-14 \\
13,14\end{array}$ & $\begin{array}{l}9.9 \\
9.8 \\
9.5 \\
2.2 \\
2.1 \\
3.5\end{array}$ & $\begin{array}{l}81 \\
125 \\
125 \\
100 \\
106 \\
32\end{array}$ & $\begin{array}{l}5.7 \\
5.7 \\
5.7 \\
11.3 \\
14 \\
13.1\end{array}$ & $\begin{array}{l}396 \\
396 \\
395 \\
369 \\
272 \\
348\end{array}$ & $\begin{array}{l}2.6 \\
2.6 \\
2.8 \\
2.4 \\
2.4 \\
4.0\end{array}$ & $\begin{array}{l}0.74 \\
0.67 \\
0.75 \\
0 \\
0 \\
0\end{array}$ \\
\hline \multicolumn{8}{|c|}{$600-A$ sbote } \\
\hline $\begin{array}{l}1009 \\
1011 \\
1014 \\
1016\end{array}$ & $\begin{array}{l}13 \\
2 \\
14 \\
12-14\end{array}$ & $\begin{array}{l}9.5 \\
4.4 \\
5.1 \\
2.1\end{array}$ & $\begin{array}{l}125 \\
18 \\
21 \\
106\end{array}$ & $\begin{array}{l}5.2 \\
8.3 \\
6.9 \\
5.0\end{array}$ & $\begin{array}{l}381 \\
253 \\
333 \\
432\end{array}$ & $\begin{array}{l}2.6 \\
2.4 \\
2.4 \\
2.4\end{array}$ & $\begin{array}{l}0.73 \\
0.20 \\
0 \\
0\end{array}$ \\
\hline \multicolumn{8}{|c|}{$800-A$ sbots } \\
\hline 1019 & 13,14 & 3.4 & 54 & 8.0 & 258 & 2.4 & 1.02 \\
\hline
\end{tabular}

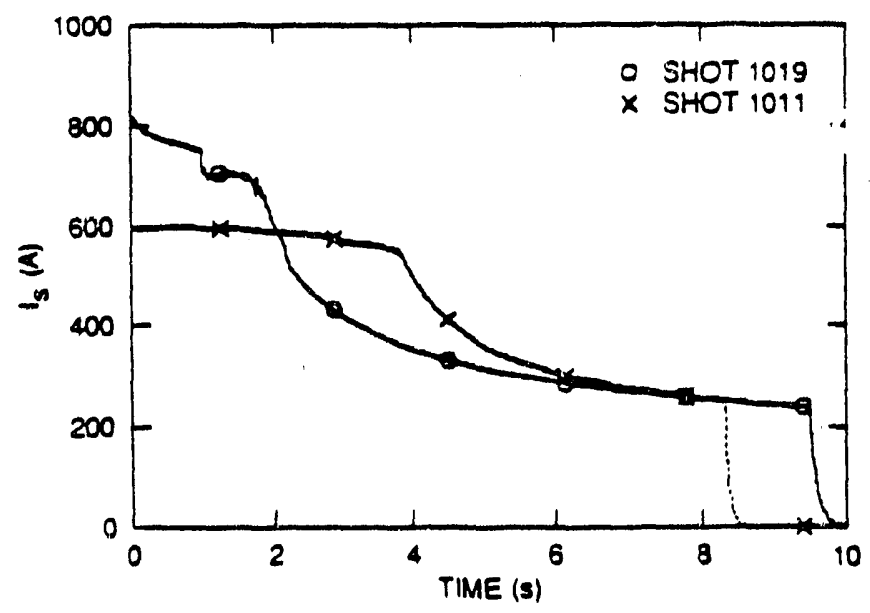

Fig. 2. Voltage traces after a beater pulse (shot 1007 ). 
in the normalized zone. The betium temperature normal voltage for VTO1-02 at $400 \mathrm{~A}$ is $12 \mathrm{mV}$. Figure 2 shows that this was surpased quickly, but the pormal front did pot reach VTO2 for another $3 \mathrm{~s}$. Thus, heating in the normalized zone due to Joule beating plays an important role in the quench bebavior of a cablein-conduit conductor.

When the sample current was kept on longer to determine whether there wa more normal zone propagation, the current dropped drastically, especially for bigher initial currents. The beating in the normalized zone preduced a roltage high enough to reach the power supply limit of $9.5 \mathrm{~V}$. This caused the pormer supply to switch to a constant-voltage mode, which lowered the current according to the load resistance. Figure 3 show typical current traces for $600-\mathrm{A}$ and $800-\mathrm{A}$ shots. Final sample curreats for all shots are listed in Table 2.

\section{Temperature Profiles}

Thermocouples located at most of the voltage tap locations measured temperature rise relative to the bath temperature at these points. This information can also be used to find the por$\mathrm{mal}$ zone propagation. Figure 4 shows the temperature traces for shot 1007. As the normal zone passed each TC location, a sharp rise in temperature was observed. Subsequent heating that gave rise to the increasing resistive voltage shown in Fig. 2 is clearly seen in this temperature plot.

While Figs. 2 and 4 give about the same time for pasage of the normal front at VTO2 and TCO2, the voltage traces sometimes showed confusing signals owing to inductive pickup. The temperature sigals are used to determine the normal fronts and the propagation velocities. Near the midpoint of the sample, the conductor was bent back to make the bifilar winding. Slight

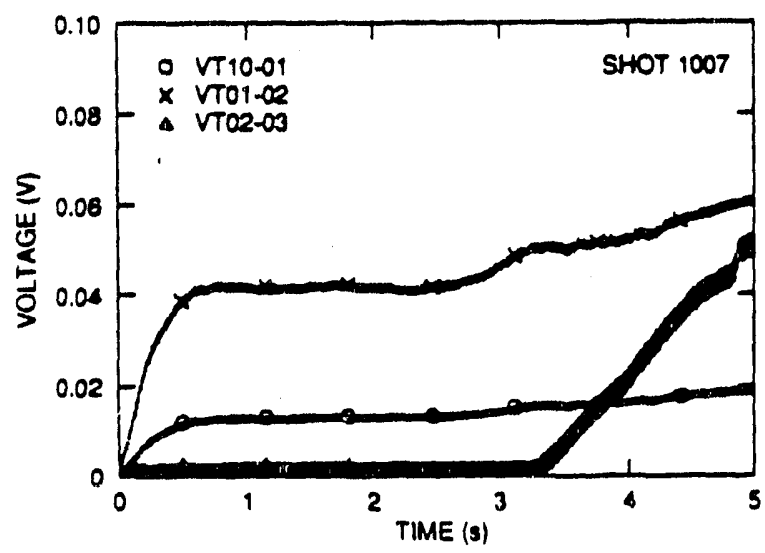

Fig. 3. Sample currents for $600-\mathrm{A}$ and $800-\mathrm{A}$ shots, showing the droop due to resistive buildup.

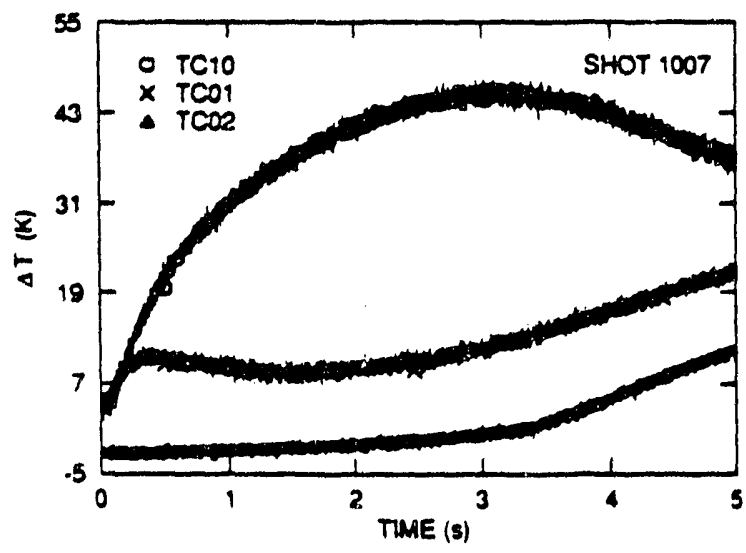

Fig. 4. Thesecouple sigasle for shot 1007
33

thermal shorting caused small premature temperature rises on some of the TC taps near the midpoints, as can be seen in Fig. 4. The time for each TC to rise $4 \mathrm{~K}$ was chosen to define the passing of the normal front.

\section{Propagation Velocities}

The normal front passing time was calculated at each TC tap location for all the shots shown in Table 2. Two distinct groups of results were obtained. One group used the short beaters (3 or 13) and was pulsed with very bigh beating energy density $\left(24 \mathrm{~J} / \mathrm{cm}^{3}\right)$. The other group used the longer heaters (12-14) and wes pulsed with much lower heating energy densily $\left(0.68 \mathrm{~J} / \mathrm{cm}^{3}\right)$. The resulting normal front positions as a function of elapeed time are plotted in Figs. 5 and 6 . In both plots, the origin of the normal front was chosen to be the upstream end of the bester, and the time when the sigal from this TC (TCO1 for Fig. 5 and TCO2 for Fig. 6) increased by $4 \mathrm{~K}$ was chowen as the zero time. (Note that in Figs. 2-4 the zero time is when the beater is pulsed.)

Shots were taken with and without imposed llow, as shown in Table 2. For shots with imposed Blow, the average velocity between successive tape was corrected for the for and the elapsed time in noflow condition was calculated. The dats in Figs. 5 and 6 reflect this correction. It is evident from these plots that the velocity increases with time. Maximum propagation velocities of about $3 \mathrm{~mm} / \mathrm{s}$ at $400 \mathrm{~A}$ and about $5 \mathrm{~m} / \mathrm{s}$ at $800 \mathrm{~A}$ are obeerved.

For the group of sbota sbown in Fig. 5 , the initial beating energy density was so large that it would take about $15 \mathrm{~s}$ of (constant) Joule beating to equal this beat. The Joule heating over the whole shot period was less than the beater pulse. "Thus, the propagation of this group of data might be dominated by the initial beating. This could explain the fact that velocities at early times in this group are much bigher than those shown in Fig. 6 for the same currents. This may also be the reason that, in this group of shots, the 600 -A data were not appreciably differeat from the 400-A date.

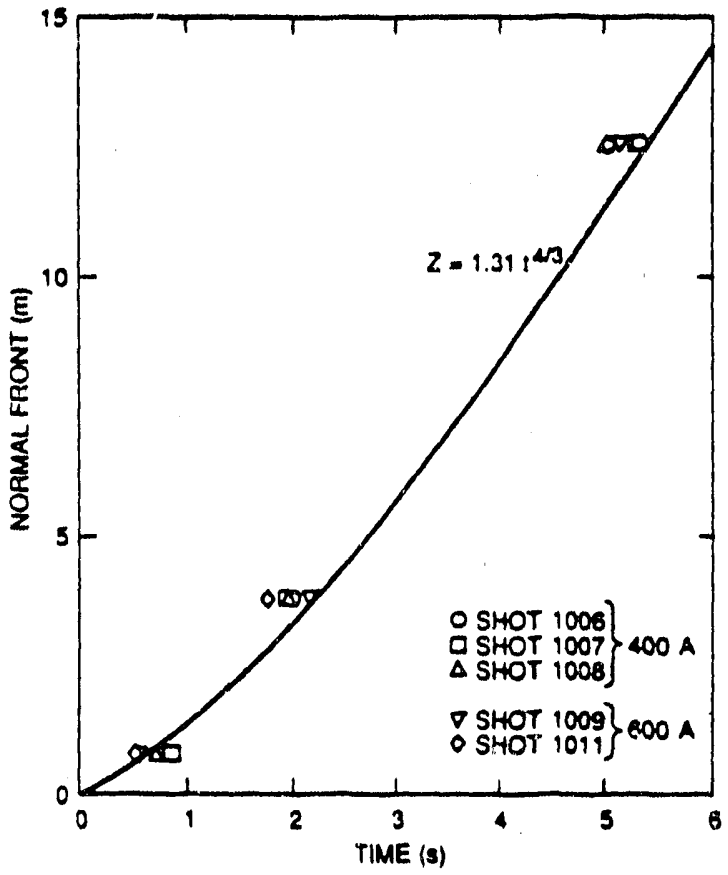

Fig. 5. Normal front position as a function of time for intensive heating shots.

\section{Discussion}

In Ref. 2, Dresper calculated that during the early part of a quench the belium in the normalized zone expands with a veloc- 


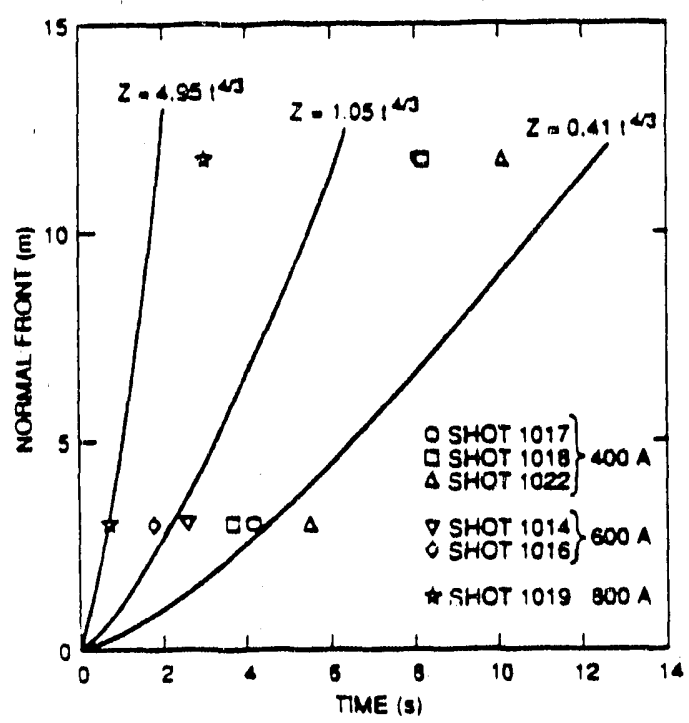

Fig. 6. Vormal frone position as a function of time for moderate heating shots.

ity that increases as the one-third power of time, or the normal zone expands as

$$
Z=Z_{0} t^{4 / 3} \text {. }
$$

We fitted the dat 3 in Figs. 5 and 6 to this power law by forcing the curve through the first (earliest messured time) data point. Although, as mentioned earlies, the data in Fig. 5 were taken under conditions quite different from those under which Eq. (1) was derived, they lie very close to the power curve over the whole propagation time.

The 400 -A data in Fig. 6. which have a lower $Z_{0}$ than those in Fig. 5, showed a significant increase from the 4/3-power curve later in time. The 800-A data went lower than the curve. This, however, may be the resuit of a curreat droop that started at about I g, as can be seen in Fig. 3. In Ref. 4, Ando found that ine propagation data ean better be fitted with a power law of 1.6. He also found a stronger dependence on conductor current than Dresuier's prediction. ${ }^{2}$ Ee attributed the discrepancy to the heating in the normalized zone. Thus, the validity of Eq. (1) and bow long in elapsed time it is applicable remain in question.

Ln Ref. 6, Dresner calculated the time of onset of THQ and the time at which the conductor over the eatire bydraulic leagt b goes norma. The onset time ton depends on the belium expansion in the normalizeci zone and is

$$
(4 f Z / D)^{3 / 2} \frac{D}{4 f t_{o \alpha}}=\left[(\partial p / \partial T)_{v} \Delta T \rrbracket / A \rho c^{2}\right.
$$

with $Z$ evaluated at to. For the 800 -A shot. $(\partial p / \partial T)_{v}=0.58 \times$ $10^{5} \mathrm{~Pa} / \mathrm{K}$ at 2.4 atm $6.3 \mathrm{~K}$. temperature difference between current sharing and basb $\Delta T=4.0 \mathrm{~K}$, density $\rho=24.9 \mathrm{~kg} / \mathrm{m}^{3}$, velocity of sound $c=131 \mathrm{~m} / \mathrm{s}$, friction factor $f=0.02$, bydraulic diameter $D=0.707 \mathrm{~mm}$, and the coefficient $A=0.34$ based ou the $t / 3$ power of $Z$ given in Fig. 6 . The onset of THQ is calculated to be $t_{\text {on }}=0.7 \mathrm{~s}$.

The time at which the conductor goes normal over the entire bydraulic length (the anigh time) is approximated by

$$
t_{1}=0.38\left(C_{p} \Delta I\right)^{1 / 4}\left(f L^{3} / c^{3} D\right)^{1 / 2} .
$$

For a specific beat $C_{p}=8400 \mathrm{~J} / \mathrm{kg} \cdot \mathrm{K}$ and a half-hydraulic leagth $L=25 \mathrm{~m}$, we find that at $800 \mathrm{~A}$ the entire conductor should go normal is less than $5.3 \mathrm{~s}$. No sharp increase in propagation was observed experimentally. Eowever, the colculated to. is about the same time that the sample current started to droop. This might have preveated further propagation and the resulting THQ.
34

Similar calculations for the 400-A shot in Fig. 6, bowerex, yielded quite contradictory results. The onset time $t_{\text {on }}=32 \mathrm{~s}$ is loager than the finish time $4=5.1 \mathrm{~s}$. Furtber examination showed that there is an additional condition for $\mathrm{Eq}$. (3) to be vaid. At to the helium expansion velocity at the initial normad tront should be much faster than ibe expulsion velocity at the open end,

$$
\dot{Z} / c>2\left(3 C_{,} \Delta T / c^{2}\right)^{1 / 4}(D / 4 f L)^{1 / 2}
$$

Based on the measured $\dot{Z}$, this condition was not met in either the 800-A or the 400-A shot conditions, and the disparity is worse in the latter shot. Applying Eqs. $(2)-(4)$ to Ando's experiment" (and using his $Z$ expression), we find similar contradictions. The onset time $t_{0}=1.2 \mathrm{~s}$ is longer than the finish time $t_{f}=0.3 \mathrm{~s}$. Again, the additional condition [Eq. (4)] was not met, and no sharp increase in propagation was observed.

\section{Conclusion}

A preliminary test has been performed to measure quench propagation in a cable-in-conduit superconductor. Altbough the data are not extensive, the behavior of the sample was similar to that reported by Ando for tests performed at the same current densities (though at 7-T Geld). The propasution increased with time, a phenomenon that can only be explained by thermal bydraulics of the coolant. The maximum propagation velocity was about $5 \mathrm{~m} / \mathrm{s}$ at a current density of $100 \mathrm{~A} / \mathrm{mmm}^{2}$.

The propagation velocity (teas of meters per second) predicted by Refs. 5 and 6 bas not been obeerved. Based on the measured initial normal zone bot belium expansion velocity, the condition for use of the Snish time formula by Dresner was not met in either the present experiment or in Ando's experiment. It is not clear whether the observer slightly bigher pover depea. deace of normal zone velocity on eiapsed time is due to changes in belium expansion velocity ur is a result of THQ. Further studies, both analytically and experimentally, are needed before the existcace of THQ can be verified.

\section{Aclenowled gument}

The authors are grateful for the assistance of W. J. Kenney in assembling the sample and $\alpha C$. T. Wilson and D. T. Fehling in setting up the data acquisition system.

\section{References}

1. J. R. Miller et al. "Pressure Rise During the Quench of a Superconducting ilagnet Using Internally Cooled Conductor," Proc. ICEC 8, Gezova, Italy (1980) p. 32.

2. L. Dresner, "The Growth of Normal Zones in Cable-inConduit Superconductors," Proc. 10th Symp. Fusion Eng., Philadelphia (1983) p. 2040.

3. J. W. Lue et al., Hot-Spot Measurements on the U.S.-LCI Coils in the IFSMTF," Proc. 12th Symp. Fusion Eng., Monterey (1987) p. 369.

4. T. Ando et al., "Propagation Velocity of the Normal Zone in a Cable-in-Conduit Conductor, " paper presented at the 1989 Cryogenic Engineering Conference, Las Angeles, 1989.

3. C. A. Luongo et a., "Thermal Hydraulic Simulation of HeLium Expulsion from a Cable-in-Conduit Conductor," IEEE Traas. Magn. 25 (1989) 1589.

6. L. Dreaner, J. W. Lue, and M. S. Lubell, "Report of the Analysis of the Large Propagation Velocities Observed in the Full-Length SSC Test Dipoles," to be published.

7. A. Devred et al., "Development of Spontaneous Quenches in Full-Lengtb SSC RS:D Dipoles," paper presented at the 1989 Particle Accelerator Conference, Chicago, 1989. 

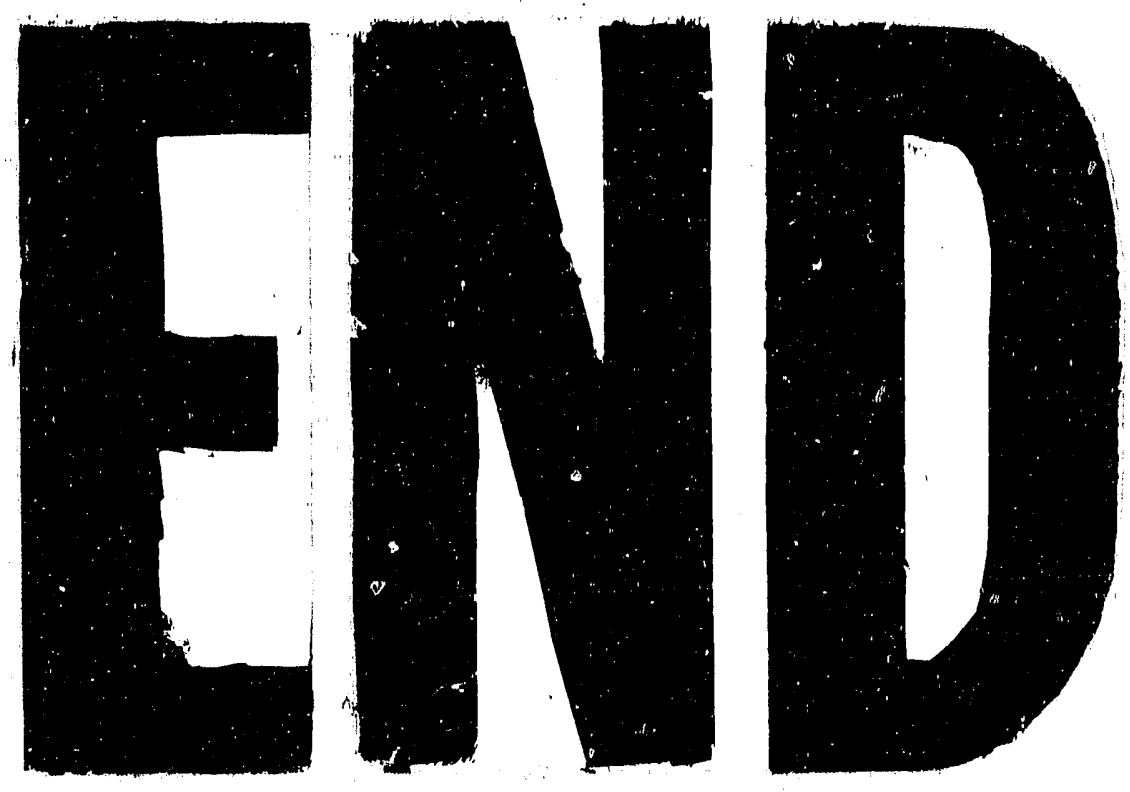

4
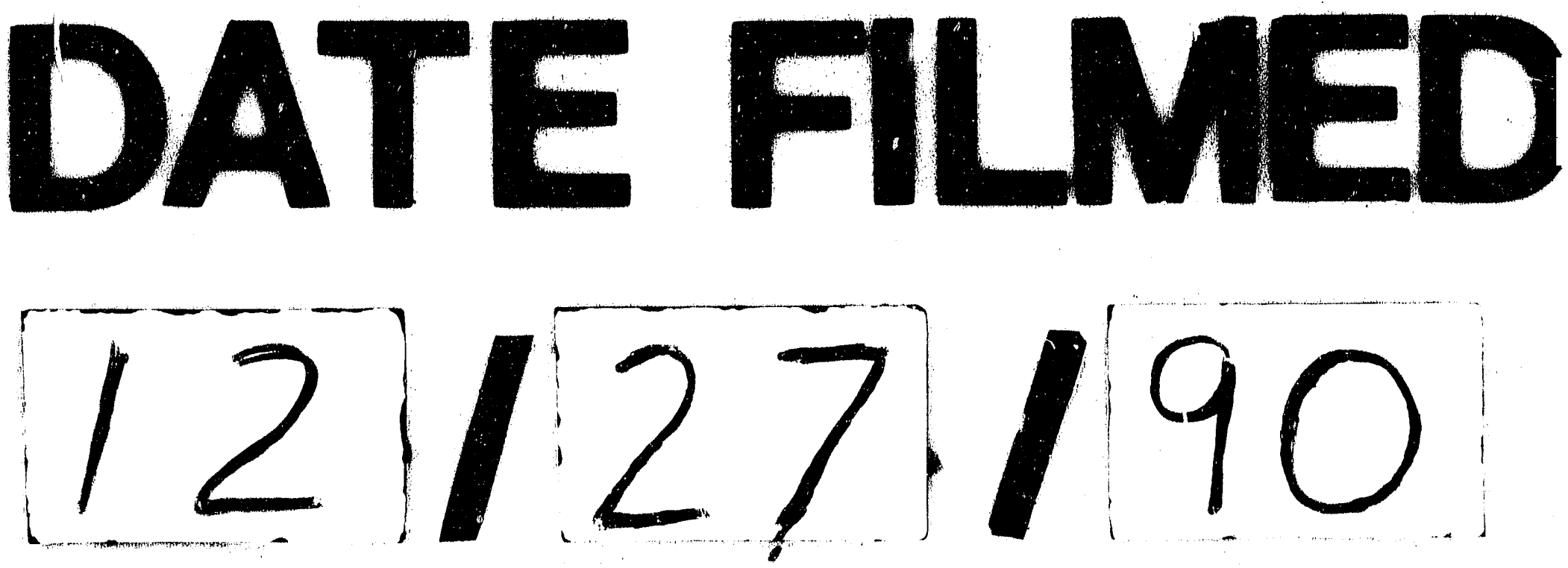
